
John H. Smith

U.S. DEPARTMENT OF COMMERCE

National Bureau of Standards

Institute for Materials Science and Engineering

Metallurgy Division

Gaithersburg, MD 20899

March 1987

Final Report

This work was sponsored by

Department of Transportation

Washington, DC 20590

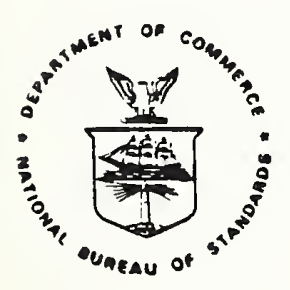

U.S. DEPARTMENT OF COMMERCE, Malcolm Baldrige, Secretary NATIONAL BUREAU OF STANDARDS, Ernest Ambler, Director 


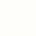




\title{
EVALUATION OF CRACKING IN ALUMINUM CYLINDERS
}

\author{
By \\ John H. Smith \\ Metallurgy Division \\ National Bureau of Standards \\ March 1987
}

Prepared For: U.S. Department of Transportation Washington, D.C. 20590 



\section{EVALUATION OF CRACKING IN ALUMINUM CYLINDERS}

INTRODUCTION:

Cracking has been observed in the threaded area of high pressure ( 4500 psi) fiberglass-wrapped composite-aluminum (DOT-E$7235)$ compressed gas cylinders and has resulted in leaking and rupture of a few cylinders in the last three years (Ref. 1 ). More recently, the neck and threaded area of some fiberglasswrapped composite-aluminum (DOT-E-7235) as well as some seamless aluminum (DOT-3AI) cylinders have been visually inspected during the normal periodic retest. As a result of this visual inspection at the time of required periodic retesting, several aluminum cylinders were reported to show evidence of cracking in the neck and threaded area. A group of cylinders was obtained for more detailed laboratory examination to determine if cracks were actually present as reported, to determine the extent of cracking, and to assess the significance of cracking. This report describes the results of laboratory tests on cylinders that were reported to have cracks.

\section{DESCRIPTION OF CYLINDERS USED IN LABORATORY TESTS:}

Eight cylinders, described in Table $I$, were obtained for detailed laboratory evaluation. These cylinders were supplied to the National Bureau of Standards (NBS) by Mr. Daniel Martin of the Marin Gas Products Company, San Rafael, California. All eight of the cylinders were manufactured by Luxfer USA Limited of Riverside, California. Each of these cylinders was rejected during the normally required hydrostatic retesting because.of cracks found in the neck and/or threaded area by careful visual inspection using an intense light and a magnifying mirror for the examination. None were reported to have experienced leaking during normal service. Five of the cylinders were solid aluminum DOT-3Al (or the predecessor type SP-6498) and three were fiberglass-wrapped composite-aluminum manufactured under exemption DOT-7235. Two of the type $3 A 1$ cylinders were used in carbon dioxide service at a service pressure of 1800 psi and the other six cylinders (both type $3 \mathrm{Al}$ and type E-7235) were used as air breathing cylinders at a service pressure of $2216 \mathrm{psi}$. The date of manufacture of the cylinders (as determined from the date of the first hydrostatic test stamped on the cylinder) ranged from May 1974 to May 1985.

The cylinders were removed from service at the time of hydrostatic retesting during the first quarter of calender year 1986. This series of cylinders was of particular interest because significant cracking had only been reported previously in the higher pressure ( 4500 psi service pressure) fiberglass- 
wrapped composite-aluminum cylinders. Verification of cracking in lower pressure ( 1800 psi and 2216 psi) DOT-3Al solid aluminum and type DOT-E-7235 hoop-wrapped Cylinders would indicate that cracking is a far more general problem and may be present in a large number of DOT-3AI specification cylinders that are widely used by industry for transporting compressed air and other gases at service pressures below 3000 psi.

\section{EXPERIMENTAL TESTS AND EXAMINATION:}

All cylinders were photographed for documentation and identification as initially received. Examples of typical cylinders are shown in Figures 1 and 2. All cylinders were then examined internally in the neck and threaded area using a fiberoptics light, a small dentist mirror and a binocular microscope at magnifications between $10 \mathrm{X}$ and $30 \mathrm{X}$. This inspection was repeated several times and by different observers to verify the presence of cracks or crack-like indications in the neck and threaded area of each cylinder. The position of all crack-like indications was marked on the outside of the cylinders.

Two cylinders (serial numbers T-256255 and WK-27055) that were thought to have significant cracks were radiographed to verify the presence of cracks. The cylinders were radiographed by shooting the $x$-ray beam through the bottom of the cylinder and placing the recording film on top of the cylinder. This was not successful and no cracks were found by this procedure.

The heads of the cylinders were then cut off and examined in more detail using a binocular microscope and viewed from the inside of the head. The crack-like indications could be seen more clearly in this way than by examination through the threaded hole with the mirrors. All cylinder heads were photographed from the inside at a magnification ranging from $2 \mathrm{X}$ to $12 \mathrm{X}$ to show the exact location and appearance of the crack-like indications. In each case, the most prominent crack-like indication was designated the "0" position and the other locations were designated as positions of the clock, i.e., 3, 6, 9, etc. An example is shown in Figure 3.

To determine the extent of cracking, each cylinder head was cut into sections. In each cylinder, the region that had the largest or most distinct crack-like indication by visual examination was first examined. For cylinders numbered T-262190, $\mathrm{T}-256255$, WK-27055, and WK-31631 three-point bend specimens were cut from the neck area at the "0" position location and broken open to delineate the extent of the crack. The extent of cracking can be clearly seen by visual examination of the fracture surface of the three-point bend specimen and the length and depth of the crack can be readily measured as shown by the example in Figure 4. 
For the remainder of the cylinders, the extent of the cracking was determined by an indirect method using measurements made on metallographic specimens. Specimens used for

metallographic examination were mounted in epoxy, polished, and etched (in a 10\% sodium hydroxide solution). In each case, the polished and etched specimens were examined in the metallurgical microscope at magnifications of approximately $9 x$ to $40 \mathrm{x}$. The specimens were successively sectioned as shown in Figure 5 so that the extent of cracking could be determined. The top of the cylinder was used as the reference surface and the length of the crack on the inner surface of the cylinder was determined by measuring the height of the metallographic specimen before examination and then successively cutting off 0.060 to $0.100-$ inch from the height of the specimen and remeasuring the height. This process was repeated until any evidence of cracking had disappeared.

The depth of the crack perpendicular to the inner surface of the cylinder (designated as D in Figure 5) was determined by first measuring the depth of the crack on the metallographic specimen section as shown in Figure 6 (designated as ' $d$ ' in Figure 5). A cross section of each of the necks of the individual cylinders was then photographed and measured, and the depth of the crack measured on the metallographic specimen section (d) and the crack length (I) were plotted on the photograph of the cylinder cross section. In this case, the extent of the cracking was reconstructed as shown in Figure 5 and was related to the thickness of the cylinder neck (designated as ' $t$ ' in Figure 5). The extent of cracking in each cylinder is described in terms of the depth of cracking perpendicular to the inner surface of the cylinder (D) relative to the thickness of the cylinder $(t), i . e ., t / D$ and the length of the crack ( 1 ) along the inner surface of the cylinder as shown in Figure 5.

\section{RESULTS :}

\section{TYPE DOT-3AI 1800 CYLINDERS}

Two cylinders (serial numbers U-53388 and U-419288) of this type were obtained. These had been used in carbon-dioxide service at a service pressure of $1800 \mathrm{psi}$.

Cylinder No. U-53388:

This cylinder was manufactured to the DOT-SP-6498 specification (the predecessor specification to DOT-3Al). The date of first hydrotest (taken as the date of manufacture) was May 1974. From markings on the cylinder, it is shown that a subsequent retest was conducted in October 1979. At the time of the next retest in 1986, visual examination of the threaded and 
neck area of the cylinder showed crack-like indications in the neck area of the cylinder and the cylinder was removed from service for further examination. The detailed visual examination conducted as part of this investigation showed crack-like indications at positions "0", "3", and "6". All the crack-like indications appeared to be approximately 1/4-inch long on the inside surface of the neck just below the straight drilled portion of the neck. Visual examination showed that none of the crack-like indications extended into the threads of the cylinder. An example of the most distinct crack-like indication found by visual examination at position "O" is shown in Figure 7.

Metallographic examination of the crack-like indication at position "0" was conducted with successive sections taken starting from the lower part of the inside of the neck of the cylinder. As shown in Figure 8, the crack-like indications were identified by metallographic examination to be distinct cracks. Multiple cracks and branching cracks were found that originatedt the root of the metal folds in the cylinder neck. The maximum depth of the crack measured on the metallographic specimen (d) was approximately 0.043 -inch and the metallographic examination showed that the crack was approximately 1/4-inch long and did not extend into the smooth drilled area outside of the neck area of the cylinder. This examination did confirm that the crack-like indications that were observed by visual examination in the neck of the cylinder were definitely cracks and that multiple cracks existed that could not be distinguished by visual observation from the folds in the neck of the cylinder. The thickness of the cylinder neck is approximately 1-1/16 inch, so as shown in Figure 9. the total depth of cracking is limited to less than 5\% of the wall thickness of the neck after 12 years of service. This amount of crack growth is not considered to be critical or to degrade the structural integrity of the cylinder at this time. Due to the limited extent of cracking at position "0", the other cracks at positions " 3 " and " 6 " were not examined metallographically at this time.

Cylinder No. U-419288:

This cylinder was manufactured to DOT specification $3 A 1$ and the date of the first hydrostatic test was May 1985. The neck and threaded area of the cylinder were examined visually in early 1986 and the cylinder was removed from service at that time due to the appearance of crack-like indications in the neck. The detailed visual examination conducted as part of this investigation showed the presence of crack-like indications at positions "0", "1", "3", "5", "6", "7", "8", "10" and "11". Al1 of the crack-like indications appeared to be approximately 1/4-inch long and none extended into the straight drilled portion of the cylinder head above the neck. An example of the most distinct crack-like indication found by visual examination at position "0" is shown in Figure 10 . 
Metallographic examination of the crack-like indication at position "0" was conducted with successive sections taken starting from the lower part of the inside of the neck of the cylinder. As shown in Figure 11, the crack-like indications were found by metallographic examination to be distinct cracks. Multiple cracks and branching cracks were found that originated at the root of the metal folds in the cylinder neck. The maximum depth of the crack measured on the metallographic specimen was approximately 0.022 inch and the metallographic examination showed that the crack was approximately 1/2-inch long but did not extend into the smooth drilled area outside of the neck area of the cylinder. This examination did confirm the crack-like indications that were observed by visual examination in the neck of the cylinder were definitely cracks and that multiple cracks existed that could not be distinguished by visual observation from the folds in the neck of the cylinder. The thickness of the cylinder neck is approximately 1-inch, so as shown in Figure 12 , the total depth of cracking is limited to less than 5\% of the wall thickness of the neck. This amount of crack growth is not considered to be critical or to degrade the structural integrity of the cylinder at this time. Due to the limited extent of cracking at position "0", the other cracks at positions " 1 " through "11" were not examined metallographically.

Summary of Test Results for the DOT-3Al 1800 Cylinders:

Both of the DOT-3Al.1800 cylinders show evidence of numerous small cracks in the neck of the cylinder below the straight drilled part below the threads. These cracks were all less than 0.050 -inch deep and were about $1 / 4$ to $3 / 4$-inch long. No deep cracks were found in either of these cylinders. It is noteworthy that distinct but shallow cracks were found in cylinder number U-419288 which had been in service for only about six months. These cracks had the same general appearance as the cracks in the cylinder number U-53388 that had been in service for

approximately 12 years. This indicates that the crack initiation occurs at the time of manufacturing or very shortly thereafter. There was no indication that significant crack propagation had occurred in either of these cylinders. Careful visual inspection using a bright light, a dentist mirror, and optical magnification of about $10 \mathrm{x}$ readily found cracks in the neck of this type of cylinders. However, it is not possible from the visual inspection alone to determine the depth of the cracks and to determine if they will significantly degrade the structural integrity of the cylinders. No evidence exists which shows that cracks of less than 0.050 -inch deep (less than 5\% of the thickness of the necks) will significantly reduce the strength of the cylinder or cause leaking unless substantial crack propagation occurs. 


\section{TYPE DOT-3AL 2216 CYLINDERS}

Three cylinders (serial numbers T-266763, T-262190, and T-256255) of this type were obtained. These cylinders were used in air breathing service and were filled with compressed air at a service pressure of $2216 \mathrm{psi}$. These cylinders were manufactured (as indicated from the date of the first hydrostatic test stamped on the cylinder) in December 1980 and January 1981. They were removed from service at the time of their first hydrostatic retest (required after 5 years service) because of the presence of crack-like indications found on inspection of the threaded and neck area of the cylinders. These cylinders were manufactured to the DOT-E-6498 specification (the predecessor to the present DOT-3Al specification).

Cylinder No. T-266763:

The detailed visual examination conducted as part of this investigation showed crack-like indications at positions "0", "2", "3", "6", and "9". All of the crack-like indications appeared to be approximately $1 / 4$ to $1 / 2$-inch long and none extended into the threaded portion of the cylinder head above the neck. An example of the most distinct crack found by visual examination at position "0" is shown in Figure 13.

Metallographic examination of the crack-like indication at position "0" was conducted with successive sections taken starting from the lower part of the inside of the neck of the cylinder. As shown in Figure 14, the crack-like indication was found by metallographic examination to be a distinct crack. Multiple cracks and branching cracks were found that originated at the root of the metal folds in the cylinder neck. The maximum depth of the crack measured on the metallographic specimen (d) was approximately 0.023 -inch and the metallographic examination showed that the crack was approximately 1/2-inch long but did not extend into the threaded area outside of the neck area of the cylinder. This examination confirmed that crack-like indications that were observed by visual examination in the neck of the cylinder were definitely cracks and that multiple cracks existed that could not be distinguished by visual observation from the folds in the neck of the cylinder. The maximum thickness of the cylinder neck is approximately 1-inch, so as shown in Figure 15, the total depth of cracking is limited to less than 5\% of the wall thickness of the neck. This amount of crack growth is not considered to be critical or to degrade the structural integrity of the cylinder unless further crack growth occurs. Due to the limited extent of cracking at position "0", the other cracks at positions "2" through " 9 " were not examined metallographically at this time. Only metallographic examination was done on this cylinder (no three-point bend specimens were tested). 
Cylinder NO. T-262190:

Visual examination showed the presence of crack-like indications at positions "0", "2", "3", "5", "6", "7", "9" and "10". The crack-like indication at position "0" was about 1 -inch long extended into the first thread and the rest of the crack-like indications were approximately 1/4- to 1/2-inch long and did not extend into the threaded portion of the cylinder head above the neck. An example of the most distinct crack found by visual examination at position " 0 " is shown in Figure 16.

A three point bend specimen was made at position " 0 " and broken open to delineate the crack. A cracked area was found at this location but appeared to be less than 0.050 -inch deep and about 1-inch long. No metallographic examination was done of the crack at position " 0 ".

Metallographic examination of the crack-like indication at position "6" was conducted with successive sections taken starting from the lower part of the inside of the neck of the cylinder. As shown in Figure 17, the crack-like indications were found by metallographic examination to be distinct cracks. Multiple cracks and branching cracks were found that originated at the root of the metal folds in the cylinder neck. The maximum depth of the crack at position "6" that was measured on the surface of the metallographic specimen (d) was approximately 0.039 -inch and the metallographic examination showed that the crack was approximately 3/8-inch long but did not extend into the threaded area outside of the neck area of the cylinder. This examination did confirm that the crack-like indications were definitely cracks and that multiple cracks existed that could not be distinguished by visual observation from the folds in the neck of the cylinder. The maximum thickness of the cylinder neck is approximately 1-1/8-inch, so as shown in Figure 18, the total depth of cracking is limited to less than 5\% of the wall thickness of the neck. This amount of crack growth is not considered to be critical or to degrade the structural integrity of the cylinder at this time. Due to the limited extent of cracking at position "6", the other cracks at positions "2" through "10" were not examined metallographically at this time.

Cylinder No. T-256255:

Visual examination showed the presence of crack-like indications at positions "0", " 3 " and "8". The crack-like indication at position "0" was about 1-inch long. The crack-like indications at positions " 3 " and "8" were approximately 1/2-inch long. None of the crack-like indications extended into the threaded portion of the cylinder head above the neck. An example of the most distinct crack-like indication found by visual examination at position "0" is shown in Figure 19. 
A three point bend specimen was made at position "0" and broken open to delineate the crack. This crack was very distinct as shown in Figure 20. The crack was about 0.30 -inch deep and 5/8-inch long. The maximum thickness of the cylinder neck is approximately 1 -inch, so the crack is nearly $1 / 3$ of the way through the neck of the cylinder. This crack clearly shows the extent of cracking that can.occur in these DOT-3Al type cylinders and shows that even a crack of this depth does not extend into the threaded area of the neck and would not be detected just by looking only at the threaded area of the cylinder. This was the largest crack that was detected in the eight cylinders that were examined in this investigation. An analysis of the structural significance of this crack was not made but it is reasonable to expect that a crack of this depth would grow to the extent that leakage of the cylinder would occur before the next required hydrostatic test. No metallographic examination was done of the crack at position "0". The scanning electron microscope examination that was done of the fracture surface and did indicate that the crack growth was by the slow crack growth mode previously found in the high pressure aluminum cylinders (Ref.2).

Metallographic examination of the crack at position "3" was conducted with successive sections taken starting from the lower part of the inside of the neck of the cylinder. As shown in Figure 21, the crack-like indications were identified by metallographic examination to be distinct cracks. Multiple cracks and branching cracks were found that originated at the root of the metal folds in the cylinder neck. The maximum depth of the crack measured on the metallographic specimen (d) at position "3" was approximately 0.020-inch deep and the metallographic examination showed that the cracks were approximately 3/4-inch long but did not extend into the threaded area outside of the neck area of the cylinder. This examination did confirm that the crack-like indications that were observed by visual examination in the neck of the cylinder were definitely cracks and that multiple cracks existed that could not be distinguished by visual observation from the fold in the neck of the cylinder.

\section{Summary of Test Results for the DOT-3Al 2216 Cylinders:}

The results of these tests show conclusively that substantial cracking can occur in DOT-3Al CYlinders at a service pressure of 2216 psi after only five years of service. This is particularly well shown by the substantial crack found in cylinder No. T-256255. Other cracks in the same cylinder and in the other two cylinders examined were less than 0.050 -inch and are not believed to be structurally significant at this time but may be initiation sites for crack propagation that in the future will degrade the structural integrity of the cylinder. From the visual inspections done in this investigation, including the 
examination on the inside of the cylinder heads at magnification levels up to $30 \mathrm{x}$, it is not possible to distinguish between the large and significant cracks (such as the one that was approximately 0.30-inch deep) and the many shallow cracks (less than 0.050-inch) that are not thought to be structurally significant. Therefore, visual examination alone is not sufficient to distinguish between those cylinders that have cracks that are likely to propagate to the point of leaking before the next hydrostatic retest and those cylinders that have cracks that are not structurally significant.

\section{TYPE DOT-E-7235 2216 HOOP WRAPPED CYLINDERS}

Three cylinders (serial numbers WK-31111, WK-32699, and WK-31631) of this type were obtained. These cylinders were used in air breathing service and were filled with compressed air at a service pressure of 2216 psi. These cylinders were manufactured (as indicated from the date of the first hydrostatic test stamped on the cylinder) in the period of January 1982 through March 1982. They were removed from service at the time of the first hydrostatic retest (required after 3 years service for hoop-wrapped cylinders) because of the presence of crack-like indications found on inspection of the threaded and neck area of the cylinders.

Cylinder No. WK-31111:

Visual examination showed the presence of crack-like indications at positions "0", "6" and "10". All the crack-like indications were approximately 1/2-inch long and none extended into the threaded portion of the cylinder head above the neck. An example of the most distinct crack found by visual examination at position "0" is shown in Figure 22. No three point bend specimens were taken from this cylinder.

Metallographic examination of the crack-like indications at position " 0 " was conducted with successive sections taken starting from the lower part of the inside of the neck of the cylinder. As shown in Figure 23 distinct cracks were found in the wall of the neck region of the cylinder. Multiple cracks and branching cracks were found that originated at the root of the metal folds in the cylinder neck. The maximum depth of the crack at position "0" that was measured on the metallographical specimen was approximately 0.031 -inch and the metallographic examination showed that the crack was approximately 1/4-inch long but did not extend into the threaded area outside of the neck area of the cylinder. This examination confirmed the crack-like indications which were observed by visual examination in the neck of the cylinder were definitely cracks and that multiple cracks existed that could not be distinguished by visual observation from the fold in the neck of the cylinder. The maximum thickness 
of the cylinder neck is approximately 3/4-inch, so as shown in Figure 24, the total depth of cracking is limited to less than 5\% of the wall thickness of the neck. This amount of crack growth is not considered to be critical or to degrade the structural integrity of the cylinder at this time. Due to the limited extent of cracking at position "0", the other crack-like indications at positions " 6 " and "10" were not examined metallographically at this time.

Cylinder No. WK-32699:

Visual examination conducted as part of this investigation showed the presence of crack-like indications at positions "0" and "2". Both crack-like indications were approximately 1/2-inch long. Neither of the crack-like indications extended into the threaded portion of the cylinder head above the neck. An example of the most distinct crack found by visual examination at position "0" is shown in Figure 25. A three point bend specimen was cut from the cylinder at position "0" and tested in an attempt to delineate the crack at this position. This specimen did not fracture at the correct position to determine the crack size in this manner. However, the size of the crack at this position could still be determined by metallographic examination.

Metallographic examination of the crack-like indication at position "0" was conducted with successive sections taken starting from the lower part of the inside of the neck of the cylinder. As shown in Figure 26, the crack-like indication was identified by metallographic examination to be a distinct crack. Multiple cracks and branching cracks were found that seemed to originate at the root of the metal folds in the cylinder neck. The maximum depth of the crack measured on the metallographic specimen (d) at position "O" was approximately 0.126-inch and the metallographic examination showed that the cracks were approximately 5/8-inch long but did not extend into the threaded area outside of the neck area of the cylinder. This is a substantial crack and indicates that substantial crack propagation had occurred during the three years that the cylinder was in service. The maximum thickness of the cylinder neck is approximately 3/4-inch, so as shown in Figure 27, the total depth of cracking was approximately $8 \%$ of the thickness of the neck. This crack clearly shows the extent of cracking that can occur in this type of hoop wrapped cylinder and shows that even a crack of this length and depth does not extend into the threaded area of the neck and would not be detected just by only inspecting the threads of the cylinder. An analysis of the structural significance of this crack was not made at this time but it is expected that a crack of this depth would grow to the extent that leakage of the cylinder could occur before the next required hydrostatic test. This examination did confirm that the cracklike indications observed by visual examination in the neck of the cylinder were definitely cracks and that multiple cracks 
existed that could not be distinguished by visual observation from the fold in the neck of the cylinder. The other crack at position "2" was not examined metallographically at this time.

Cylinder No. Wk-31631:

The detailed visual examination conducted as part of this investigation showed the presence of crack-like indications at positions "0," "1","2","3","5","6" "8", "9", "10", and "11. The crack-like indications were approximately 1/2-inch long and that none extended into the threaded area of the cylinder head above the neck. An example of the most distinct crack-like indication found by visual examination at position "0" is shown in Figure 28. A three point bend specimen was cut from the cylinder at position " 0 " and tested in an attempt to delineate the crack at this position. This specimen did not fracture at the correct position to determine the crack size in this manner. However, the size of the crack at this position could still be determined by metallographic examination.

Metallographic examination of the crack-like indication at position "0" was conducted with successive sections taken starting from the lower part of the inside of the neck of the cylinder. As shown in Figure 29, distinct cracks were found in the wall of the neck region of the cylinder. Multiple cracks and branching cracks were found that originated at the root of the metal folds in the cylinder neck. The depth of the largest crack measured on the metallographic specimen (d) at position "0" was. approximately 0.236 -inch and the metallographic examination showed that the crack was approximately 5/8-inch long but did not extend into the threaded area outside of the neck area of the cylinder. This is a substantial crack and indicates that substantial crack propagation has occurred during the three years that the cylinder was in service. The maximum thickness of the cylinder neck is approximately $3 / 4$-inch, so as shown in Figure 30, the total depth of cracking was approximately 15\% of the thickness of the neck. This crack clearly shows the extent of cracking that can occur in these hoop wrapped cylinders and shows that even a crack of this depth does not extend into the threaded area of the neck and would not be detected by only looking at the threads of the cylinder. An analysis of the structural significance of this crack was not made at this time but it is expected that a crack of this depth would be expected to grow to the extent that leakage of the cylinder would occur before the next required hydrostatic test. This examination did confirm that the crack-like indications observed by visual examination in the neck of the cylinder were definitely cracks and that multiple cracks existed that could not be distinguished by visual observation from the fold in the neck of the cylinder. The other crack-like indications at positions "1" through "11", were not examined metallographically at this time. 
Summary of Results on DOT-E-7235 2216 Cylinders:

Two of the three DOT-E-7235 2216 hoop-wrapped cylinders showed significant cracks that were from $8 \%$ to $15 \%$ through the thickness of the neck of the cylinder after only three years of normal service. This indicates that this cylinder series is definitely subject to crack propagation during normal service.

From the visual inspections done in this investigation, including the examination on the inside of the cylinder heads at magnification levels up to $30 \mathrm{x}$, it is not possible to distinguish between the large and significant cracks and the many shallow cracks (less than 0.050-inch) that are not thought to be structurally significant. Therefore, visual examination alone is not sufficient to distinguish between cylinders that have cracks that are likely to propagate to the point of leaking before the next hydrostatic retest and those vessels that have cracks that are not structurally significant.

\section{DISCUSSION :}

The present investigation on a group of DOT-3AI and hoop-wrapped composite-aluminum (DOT-E-7235) cylinders shows that all of the cylinders contained cracks in the neck area of the cylinders, as shown in Table II. In all cases examined there were multiple, branched cracks originating at the root of folds in the neck of the cylinders. These cracks were generally less than 0.050-inch deep and were up to approximately 1-inch long. These shallow cracks can form the initiation sites for further crack propagation during the life of the cylinder. Similar cracking has been recently reported by investigations done by Alcan Ltd. (Ref. 2) where it was concluded that the shallow cracks are thought to be created at the time of or shortly after the cylinder is manufactured.

In the DOT-3Al cylinders with a marked service pressure of 1800 psi used to transport carbide dioxide, only the shallow cracks were found (less than 0.050-inch). However, in both the DOT-3Al and hoop-wrapped composite-aluminum (DOT-E-7235) cylinders operated at 2216 psi service pressure with compressed air, one or more of each type of cylinder had deeper cracks that are believed to indicate the occurrence of substantial crack propagation during service. This indicates that the higher stresses produced in the cylinder neck at a service pressure of 2216 psi cause an increase in the crack growth rate. At the time of the first required hydrostatic retest, cracks had propagated up to approximately $1 / 3$ of the way through the thickness of the neck of the cylinders. This represents substantial crack propagation during normal service. Such crack propagation can reasonably be expected to extend to the point where these cylinders could leak before the next required hydrostatic retest. 
From the visual inspections done in this investigation, including the examination on the inside of the cylinder heads at magnification levels up to $30 \mathrm{x}$, it is not possible to distinguish between the large and significant cracks and the many shallow cracks (less than 0.050 -inch) that are not thought to be structurally significant. Therefore, visual examination alone is not sufficient to distinguish between those cylinders that have cracks that are likely to propagate to the point of leaking before the next hydrostatic retest and those cylinders that have cracks that are not structurally significant at the time of inspection.

\section{CONCLUSIONS:}

1. Shallow cracks (less than 0.050-inch deep) were found in all of the DOT-3AI and hoop-wrapped compositealuminum (DOT-E-7235) cylinders that were examined as part of this investigation.

2. Deep cracks that may be structurally significant and are expected to propagate in service were found in one of the three DOT-3AI and two of the three hoop-wrapped composite-aluminum cylinders that had been operated at a service pressure of $2216 \mathrm{psi}$. No deep cracks were found in the DOT-3Al cylinders designed for and marked 1800 psi service pressure, that were in carbon dioxide service.

3. None of the cracks found in this group of cylinders propagated beyond the neck of the cylinder and into the threads of the cylinder even when the cracks were up to approximately $1 / 3$ of the way through the thickness of the neck.

4. By any of the visual or optical inspection methods used, it was not possible to distinguish between the shallow cracks (less than 0.050-inch) that are not thought to be structurally significant and the deep cracks that have propagated through a large portion of the cylinder neck and are thought to be structurally significant. 
RECOMMENDATIONS:

1. Additional inspections of cylinders that have been in service for varying lengths of time should be conducted to determine if all DOT-3AI and hoop-wrapped compositealuminum (DOT-E-7235) cylinders are subject to cracking and to determine if service pressure, time of use, and commodity carried have a significant effect on the cracking.

2. As a minimum, careful visual inspection should be required of the threaded and neck area of all aluminum and hoop-wrapped composite-aluminum cylinders at the time of the of the required periodic hydrostatic retest.

3. Continued efforts should be made to develop a method to accurately determine the depth of the cracks so that only those cylinders that have shown substantial crack propagation will be rejected during inspection.

4. All newly manufactured cylinders should be carefully inspected for the presence of cracks. Cylinders having evidence of cracks should be rejected or treated to remove the cracks. 


\section{REFERENCES :}

1. A.R. Woodward, "Examination of Type L45W Gas Cylinder Manufactured by Luxfer USA Ltd.", Report by Luxfer Holdings Ltd., May 1984 .

2. N.J.H. Holroyd and A.R. Woodward, "Report on Study of Cracking in Aluminum Fibre-Wound High Pressure Gas Cylinders", Report by Luxfer Holdings Ltd., Aug. 1986. 
TABLE I

\section{DESCRIPTION OF CYLINDERS EXAMINED}

\begin{tabular}{|c|c|c|c|c|}
\hline $\begin{array}{l}\text { Cylinder } \\
\text { Number }\end{array}$ & $\begin{array}{l}\text { Type } \\
\text { of } \\
\text { Cylinder }\end{array}$ & $\begin{array}{l}\text { Service } \\
\text { Pressure } \\
\text { (psi) }\end{array}$ & Gas & $\begin{array}{l}\text { Date of } \\
\text { Manufacture }\end{array}$ \\
\hline$U-53388$ & $3 A 1$ & 1800 & $\mathrm{CO} 2$ & $5 / 74$ \\
\hline$U-419288$ & $3 \mathrm{AI}$ & 1800 & $\mathrm{CO} 2$ & $5 / 85$ \\
\hline$T-262190$ & $3 A I$ & 2216 & Air & $3 / 81$ \\
\hline$T-266763$ & $3 A 1$ & 2216 & Air & $3 / 81$ \\
\hline$T-256255$ & $3 A I$ & 2216 & Air & $12 / 80$ \\
\hline WK-32699 & Composite & 2216 & Air & $3 / 82$ \\
\hline$W K-31631$ & Composite & 2216 & Air & $2 / 82$ \\
\hline$W K-31111$ & Composite & 2216 & Air & $1 / 82$ \\
\hline
\end{tabular}


TABLE II

\section{EXTENT OF CRACKING IN EACH CYLINDER}

\begin{tabular}{|c|c|c|c|c|c|}
\hline $\begin{array}{l}\text { Cylinder } \\
\text { Number }\end{array}$ & $\begin{array}{l}\text { Cylinder } \\
\text { Type/ } \\
\text { Pressure }\end{array}$ & $\begin{array}{l}\text { Crack Depth } \\
\text { Measured on } \\
\text { Metallographic } \\
\text { Specimen } \\
\quad \text { (d) } \\
\quad \text { (in.) }\end{array}$ & $\begin{array}{l}\text { Maximum } \\
\text { Crack } \\
\text { Length } \\
\text { (I) } \\
\text { (in.) }\end{array}$ & $\begin{array}{l}\text { Crack } \\
\text { Depth } \\
\text { Through } \\
\text { Cylinder } \\
\text { Wall } \\
\text { (D) } \\
\text { (in.) }\end{array}$ & $\begin{array}{l}\text { Crack } \\
\text { Depth/ } \\
\text { Thick. } \\
(\mathrm{D} / \mathrm{t}) \\
\left(\frac{\circ}{0}\right)\end{array}$ \\
\hline$U-53388$ & $3 A I-1800$ & 0.043 & $1 / 4$ & 0.040 & 4 \\
\hline U- 419288 & $3 A I-1800$ & 0.022 & $1 / 2$ & 0.030 & 2 \\
\hline$T-266763$ & $3 A 1-2216$ & 0.023 & $1 / 2$ & 0.020 & 2 \\
\hline $\mathrm{T}-262190$ & $3 A 1-2216$ & 0.039 & $3 / 8$ & 0.040 & 4 \\
\hline$T-256255$ & $3 A 1-2216$ & ---- & $5 / 8$ & 0.300 & 30 \\
\hline WK-31111 & $\begin{array}{l}\text { Hoop-Wrapped } \\
2216\end{array}$ & 0.031 & $1 / 4$ & 0.040 & 5 \\
\hline WK-32699 & $\begin{array}{l}\text { Hoop Wrapped } \\
2216\end{array}$ & 0.126 & $5 / 8$ & 0.060 & 8 \\
\hline WK-31631 & $\begin{array}{l}\text { Hoop-Wrapped } \\
2216\end{array}$ & 0.236 & $5 / 8$ & 0.110 & 15 \\
\hline
\end{tabular}

d -- depth of crack measured on metallographic specimen

D -- depth of crack perpendicular to the inner surface of the cylinder

1 -- length of crack along inner surface of cylinder

$D / t$-- depth of penetration of crack through thickness of cylinder neck 



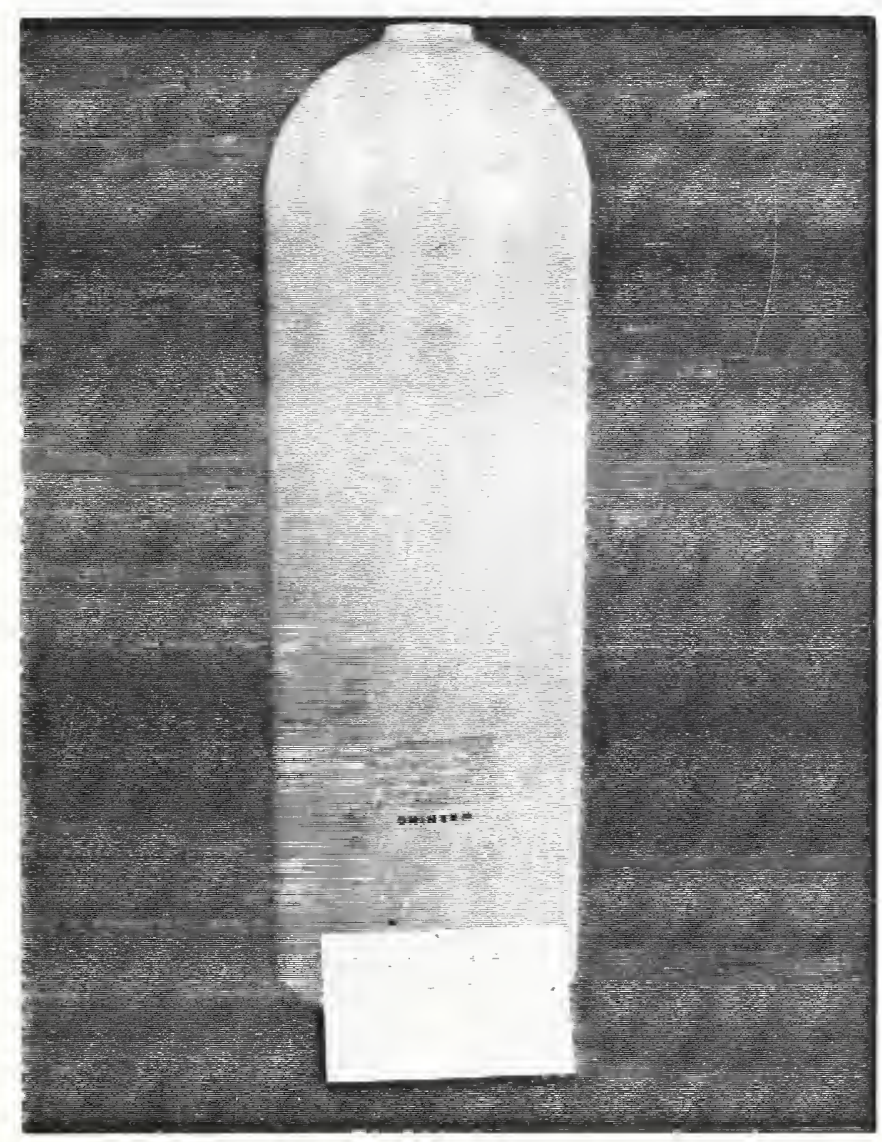

Example of Type 3 Al Cylinder

Fig. 1 


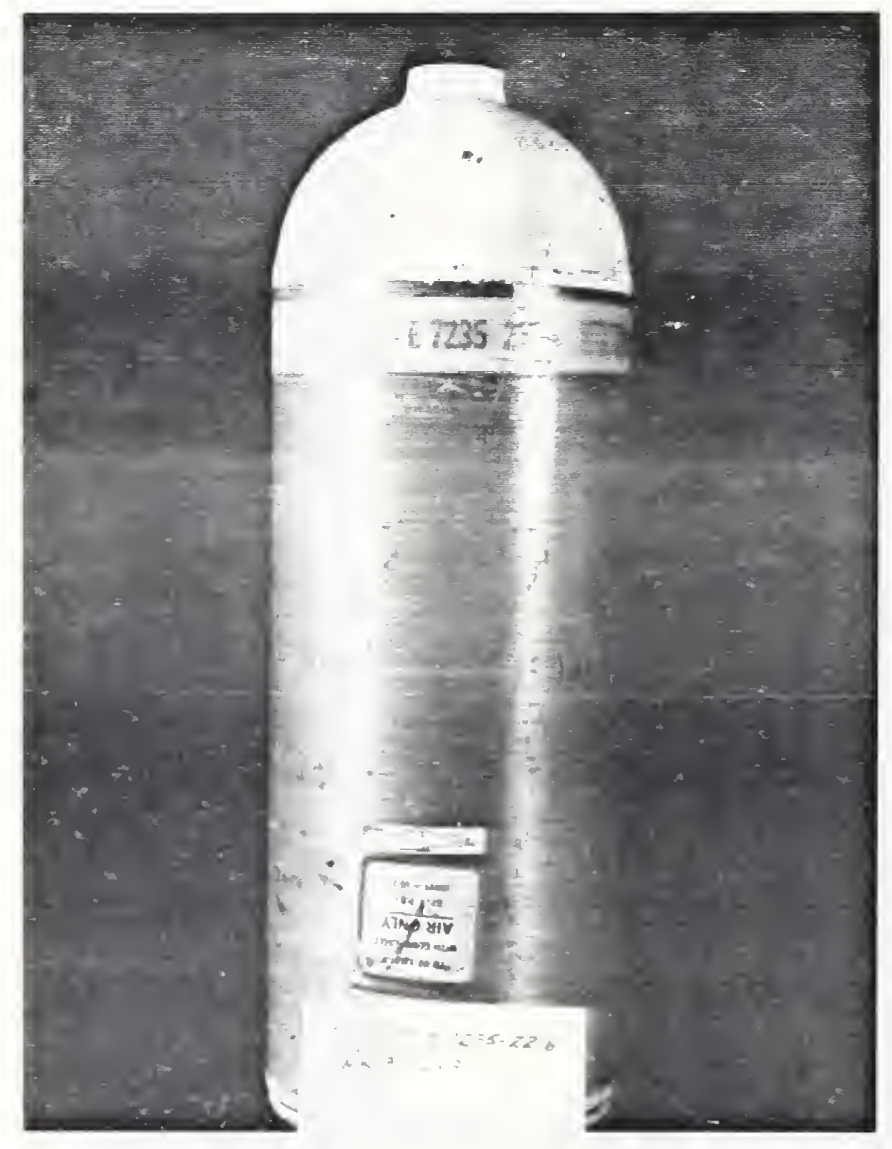

Example of Hoop-Wrapped Cylinder

Fig. 2 


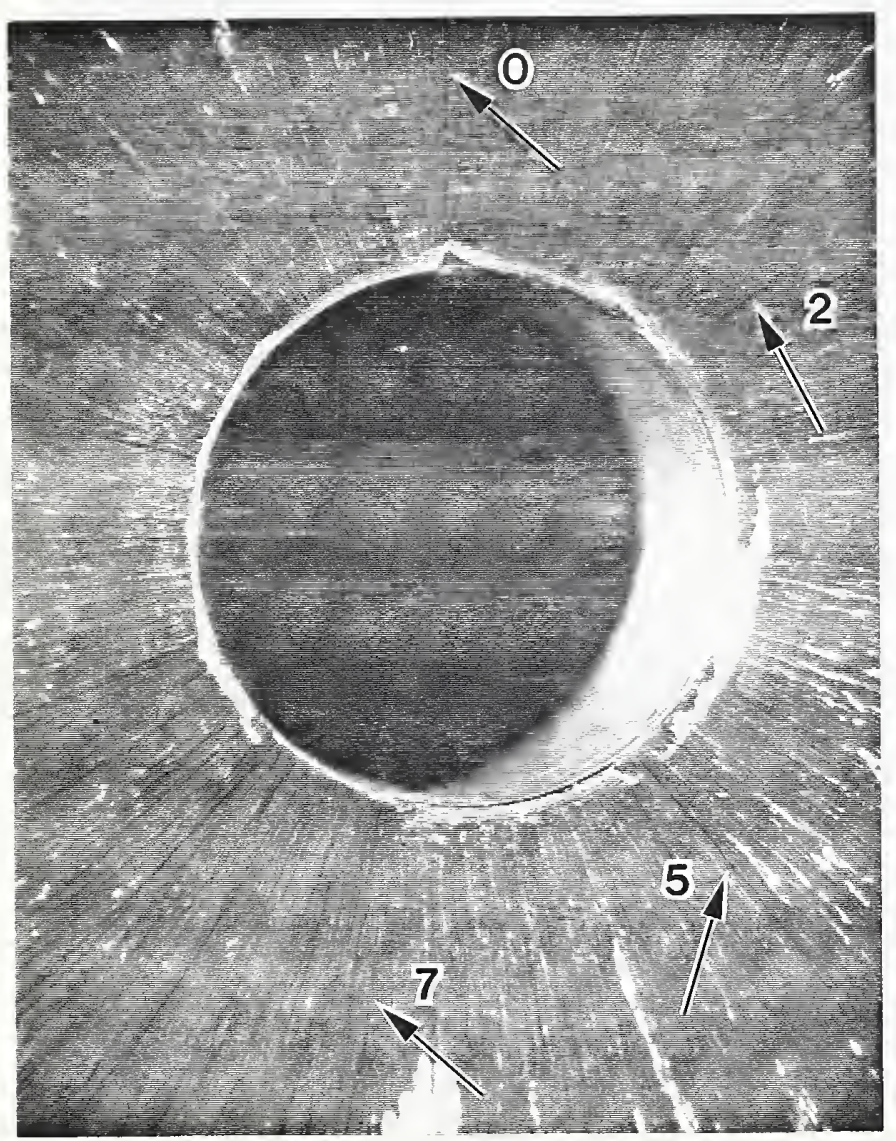

(Numbers Show Position of Cracks)

Macroscopic View of Inside of

Cylinder Head Mag. 3x

Fig. 3 


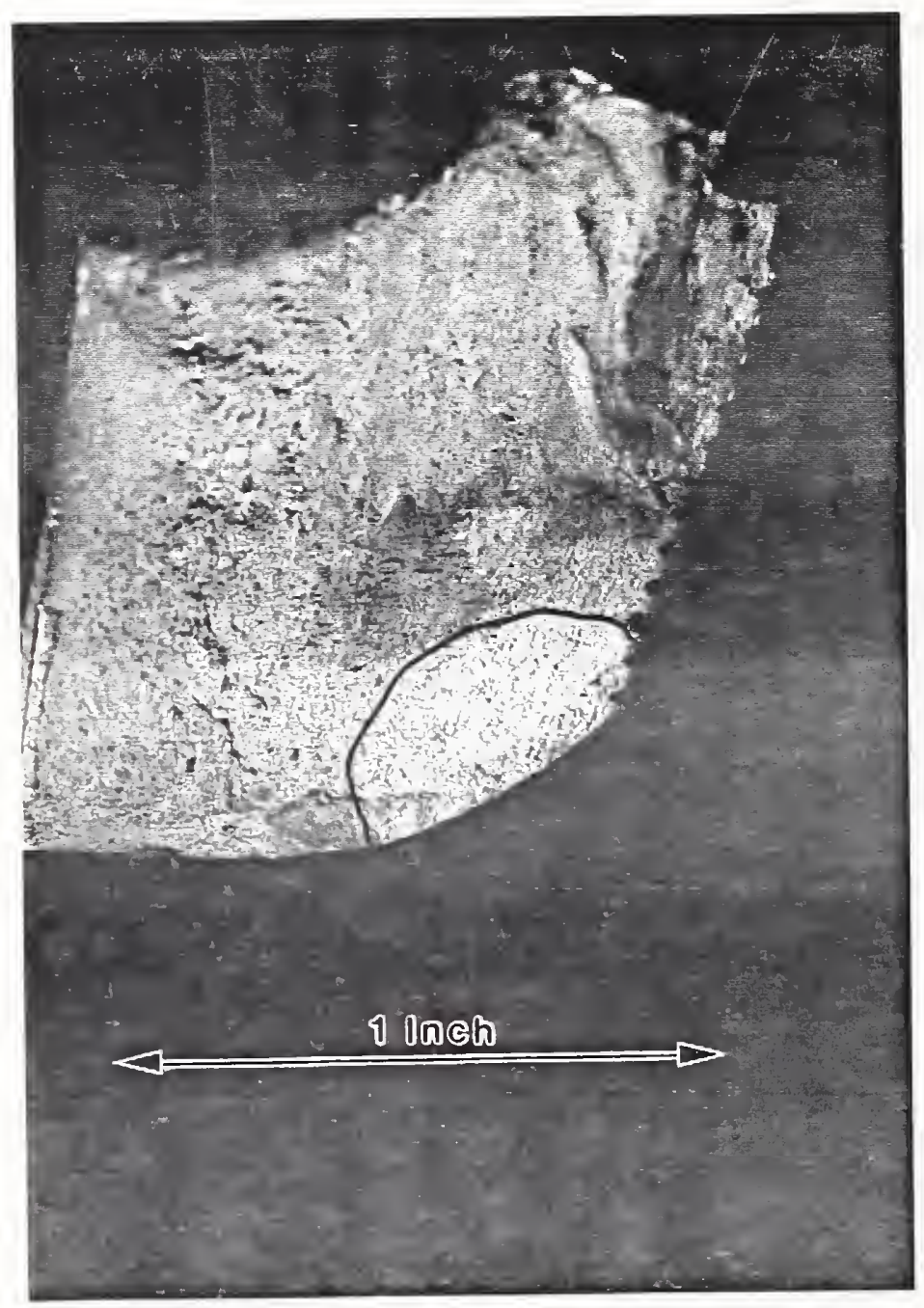

Example of Cracked Area in

Three-Point Bend Specimen

Fig. 4 


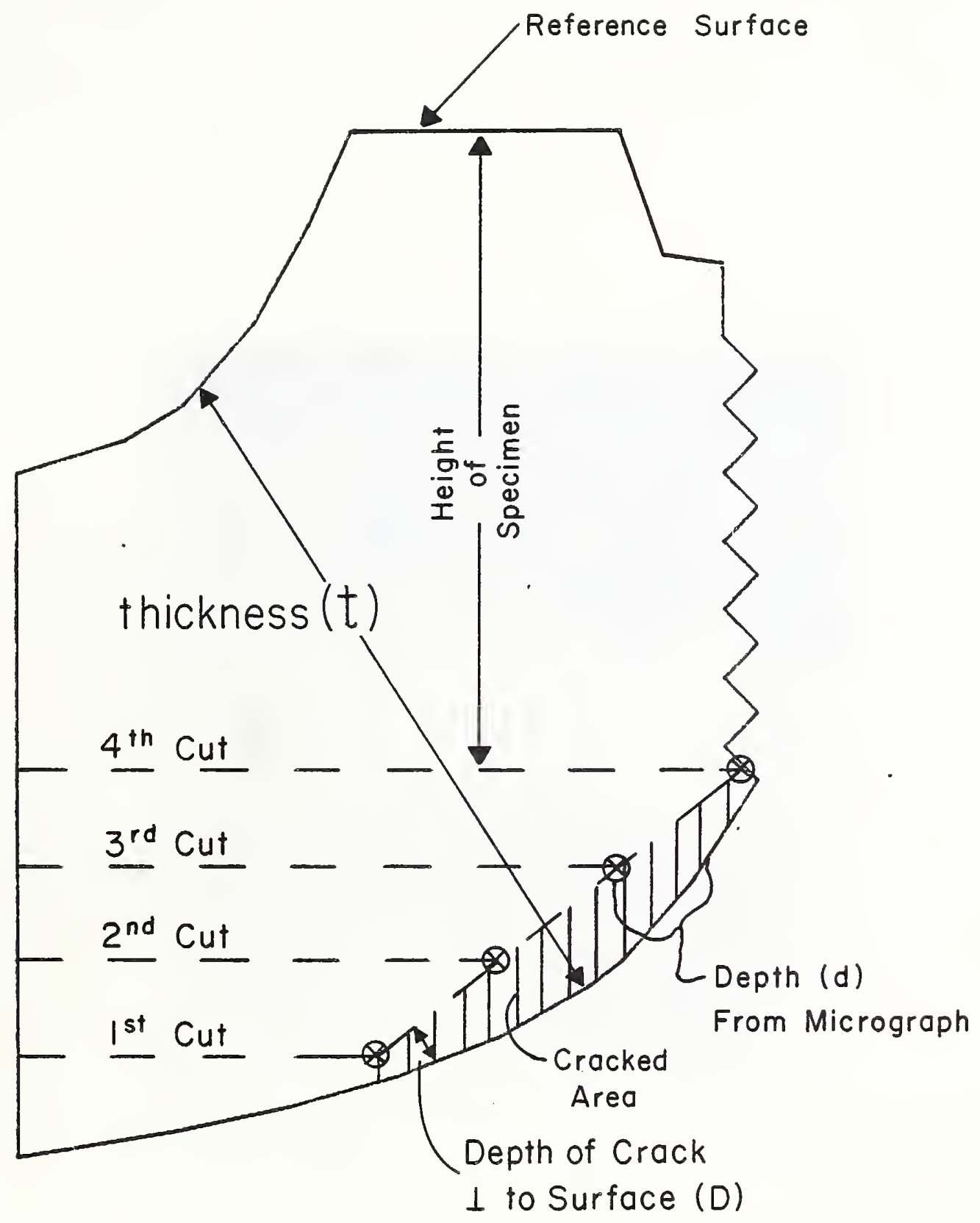

Procedure for sectioning

of Specimen

Fig. 5 


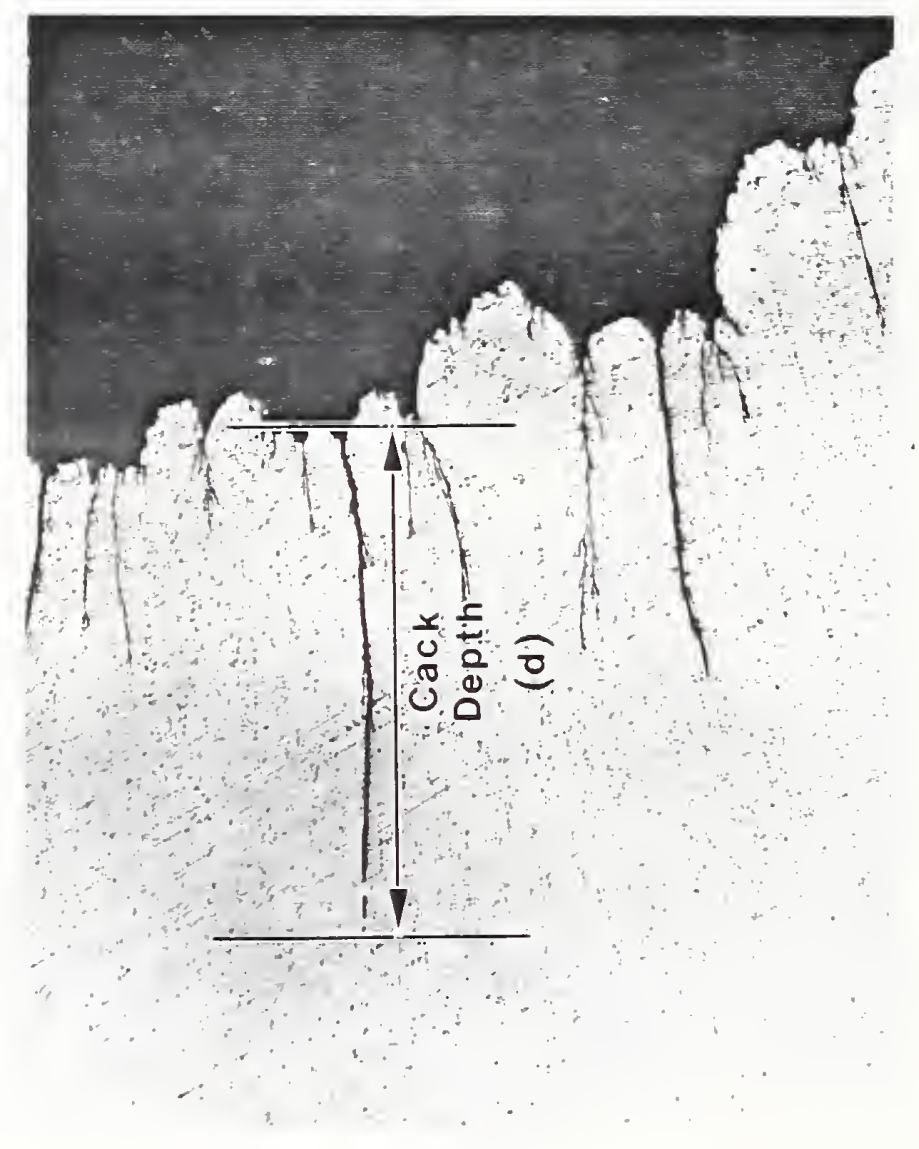

Method of Measuring Crack Depth on Metallographic specimen

Fig. 6 


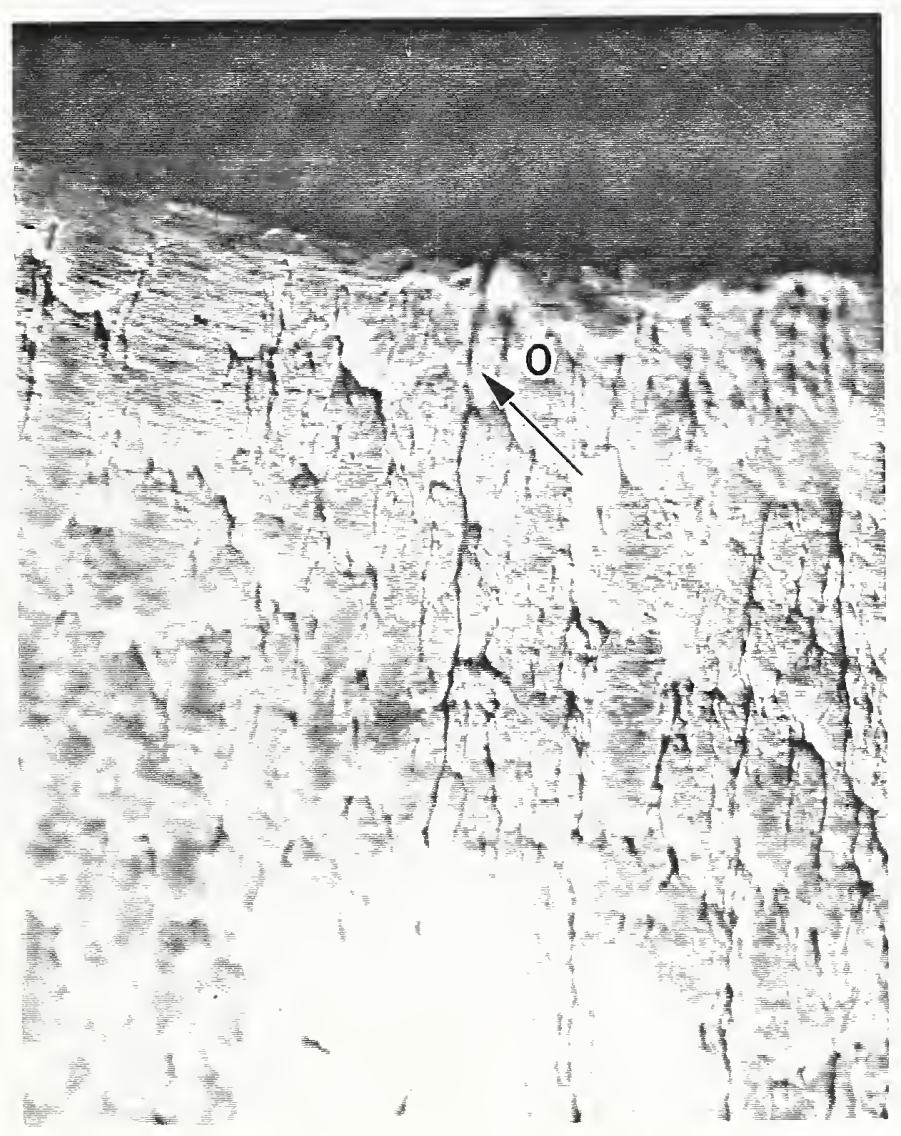

Crack-Like Indication

Cyl. No. U-53388 Mag. 10x

Fig. 7 


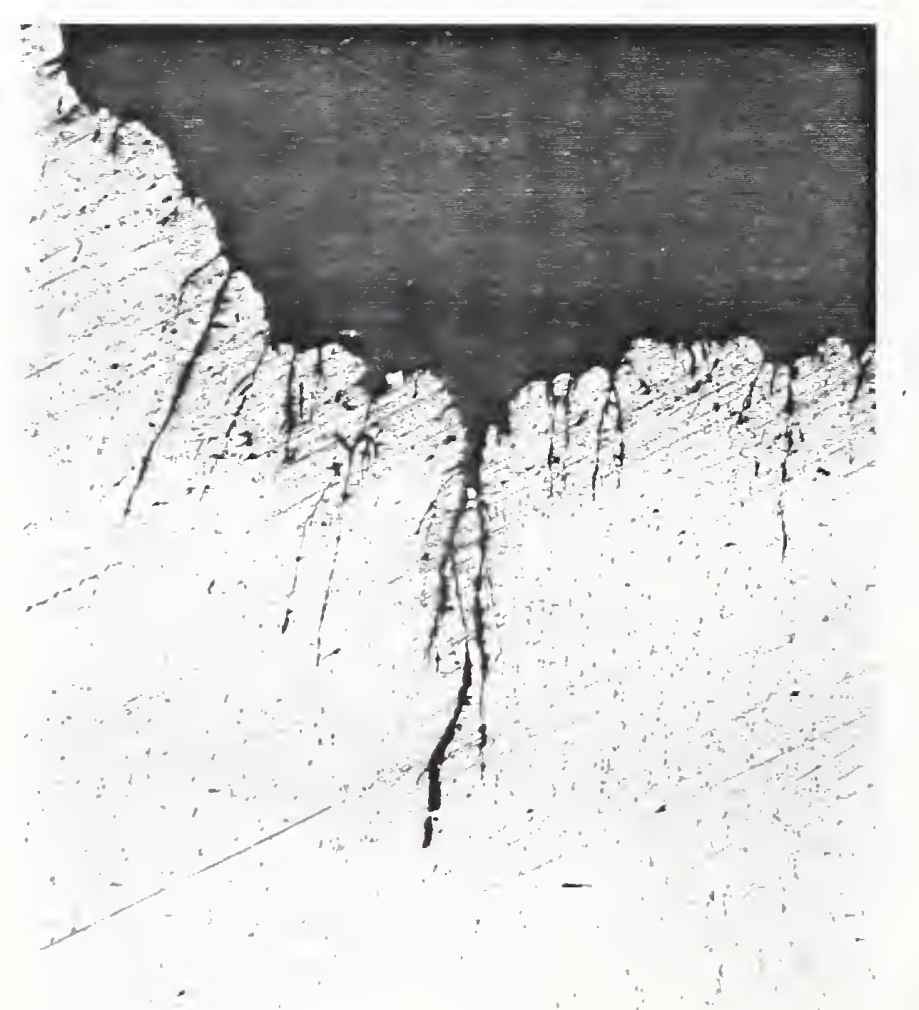

Primary Crack in Cylinder Neck

$$
\begin{gathered}
\text { CYI. No. U-53388 Mag. } 40 \mathrm{x} \\
\text { Fig. } 8
\end{gathered}
$$




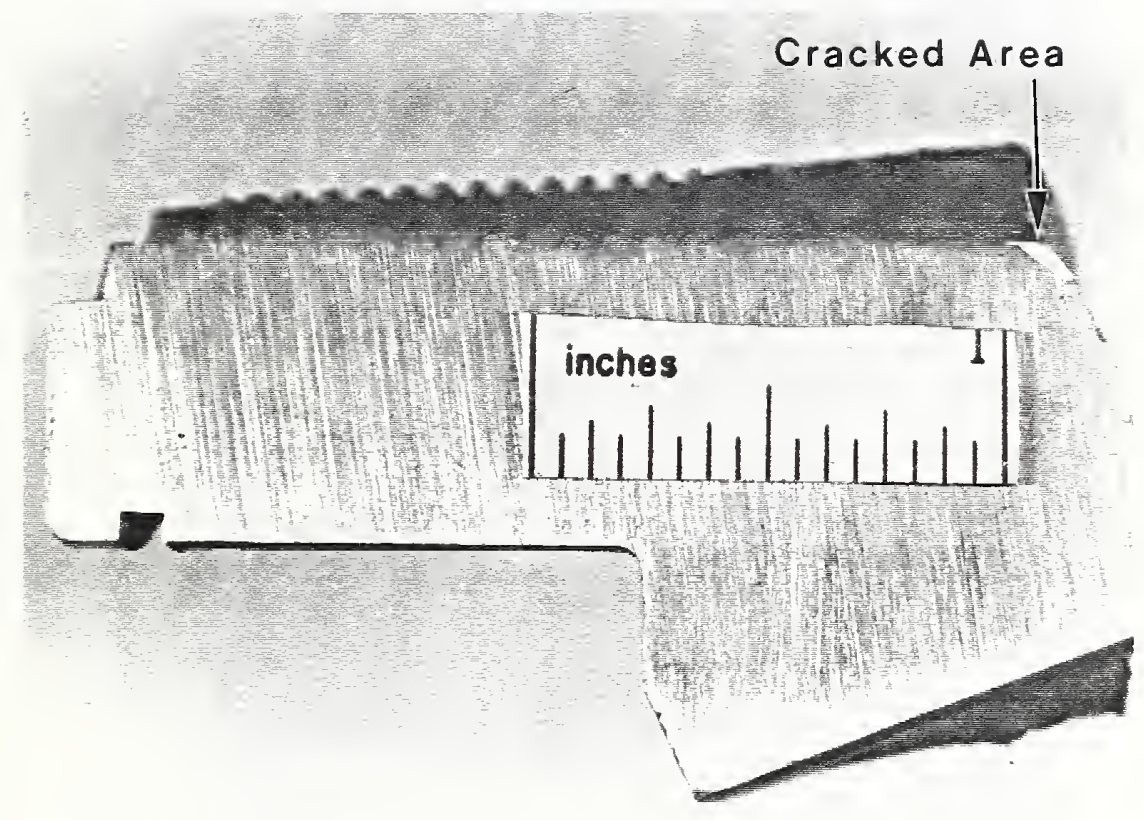

Extent of Primary Crack

Cyl. No. U-53388

Fig. 9 


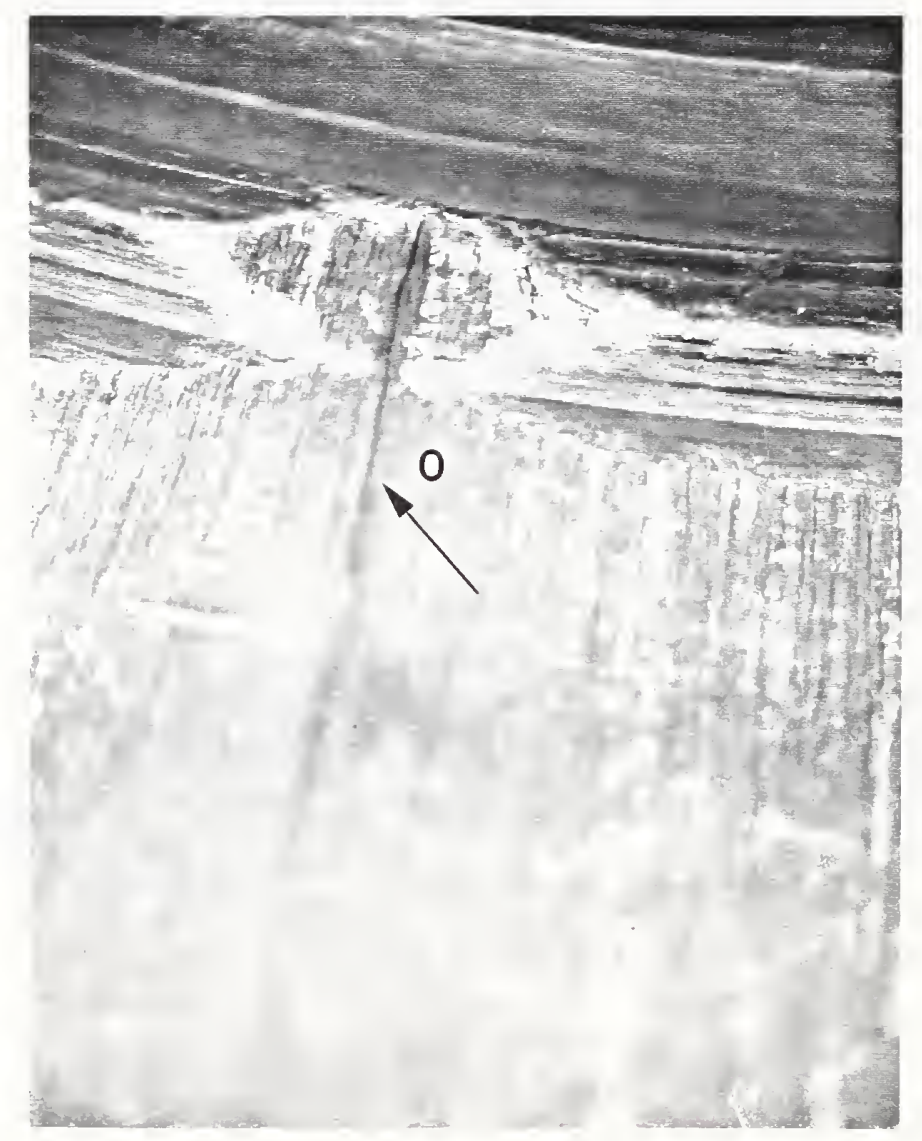

Crack-Like Indication

CY1. No. U-419288 Mag. $6 \mathrm{x}$

Fig. 10 


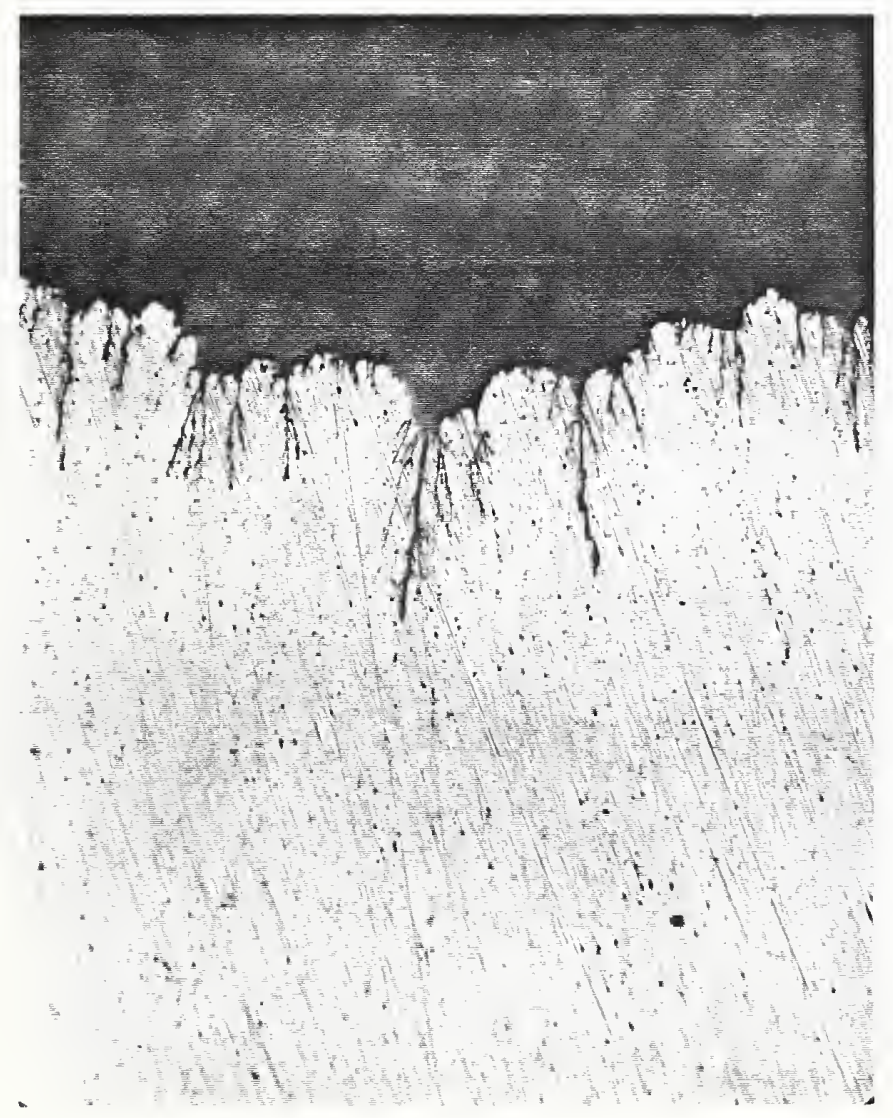

Primary Crack in Cylinder Neck

Cyl. No. U-419288 Mag. $40 \mathrm{x}$

Fig. 11 


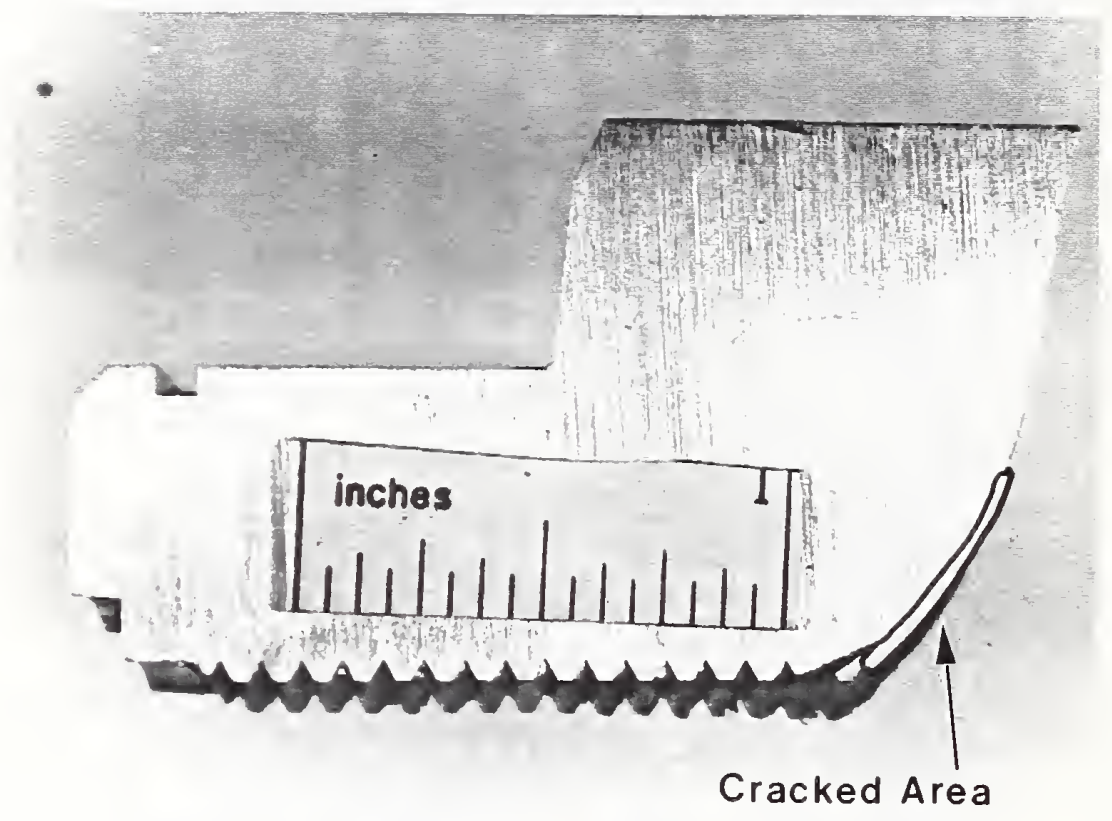

Extent of Primary Crack

Cyl. No. U-419288

Fig. 12 


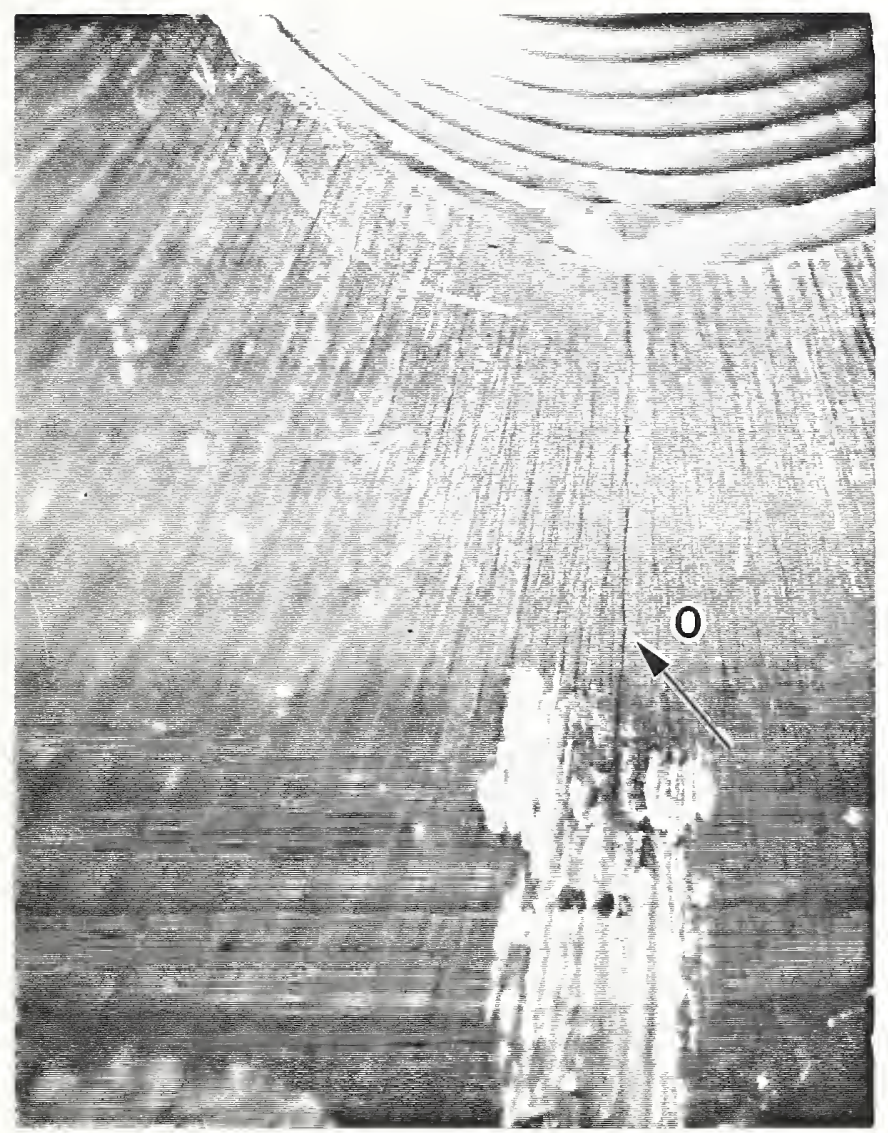

Crack-Iike Indication

Cyl. No. T-266763 Mag. 10x

Fig. 13 


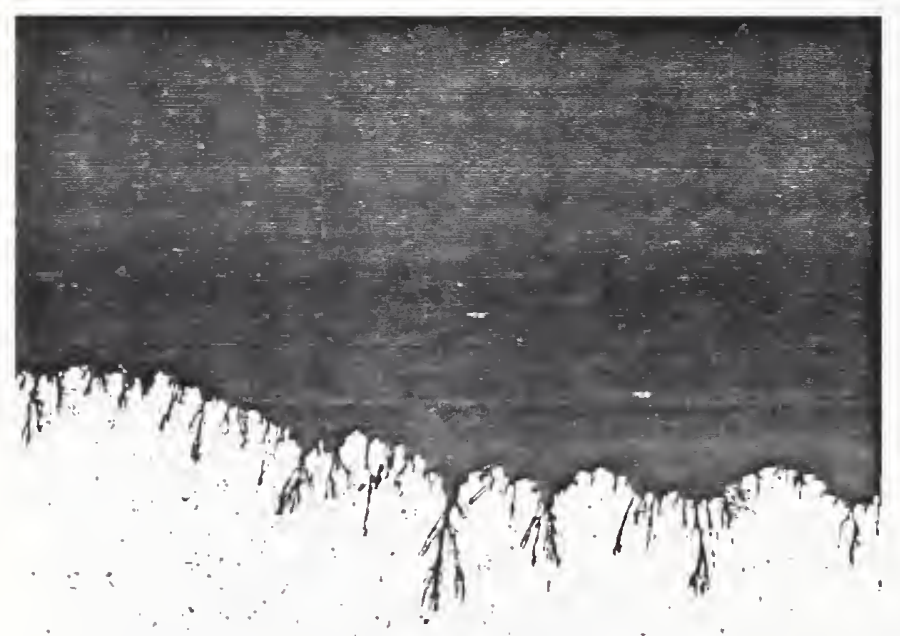

Primary Crack in Cylinder Neck Cyl. No. T-266763 Mag. 40x

Fig. 14 


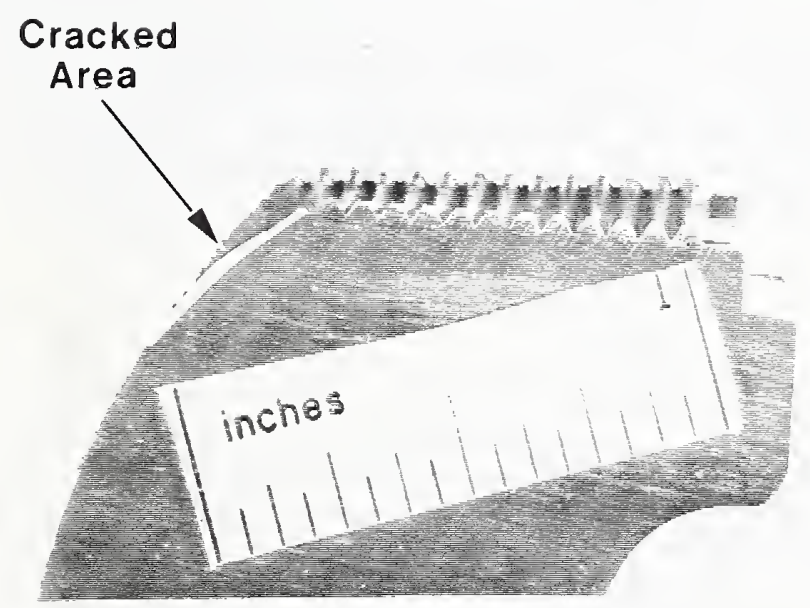

Extent of Primary Crack

Cyl. No. T-266763

Fig. 15 


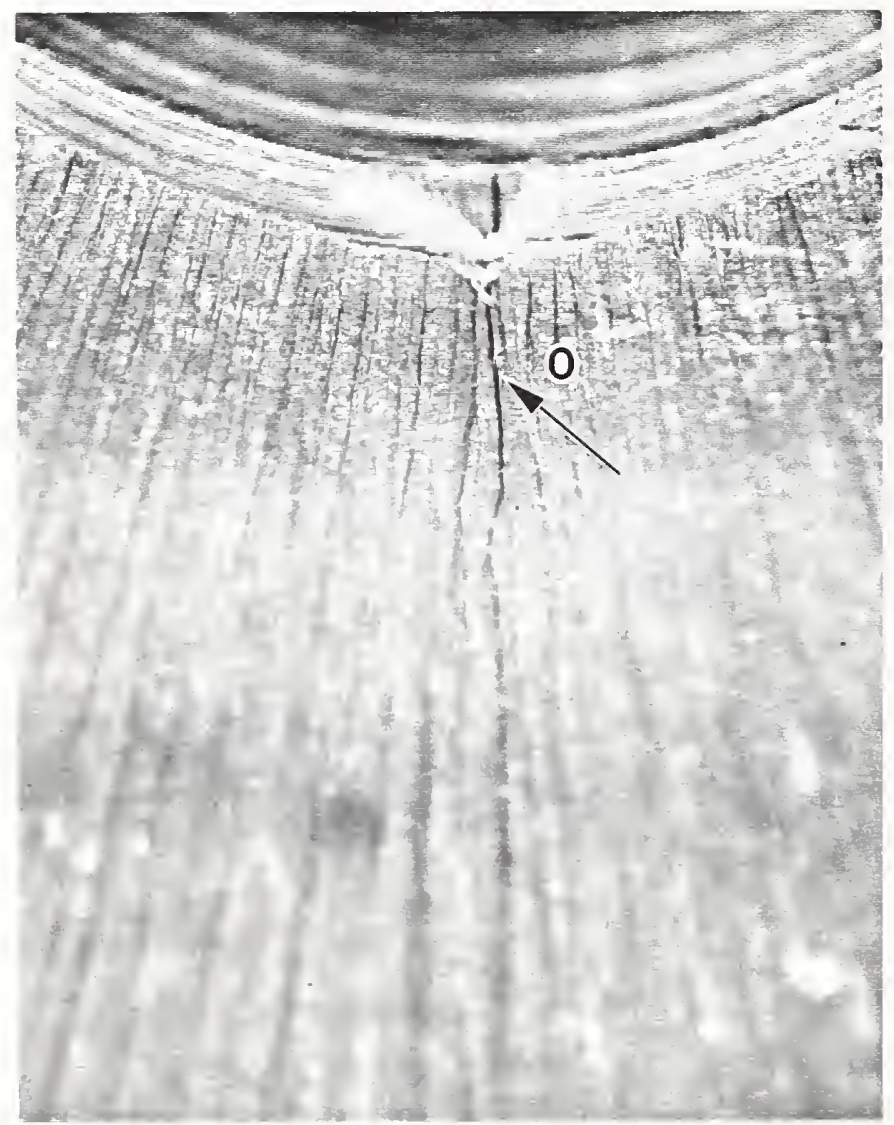

Crack-Like Indication

Cyl. No. T-262190 Mag. 10x

Fig. 16 


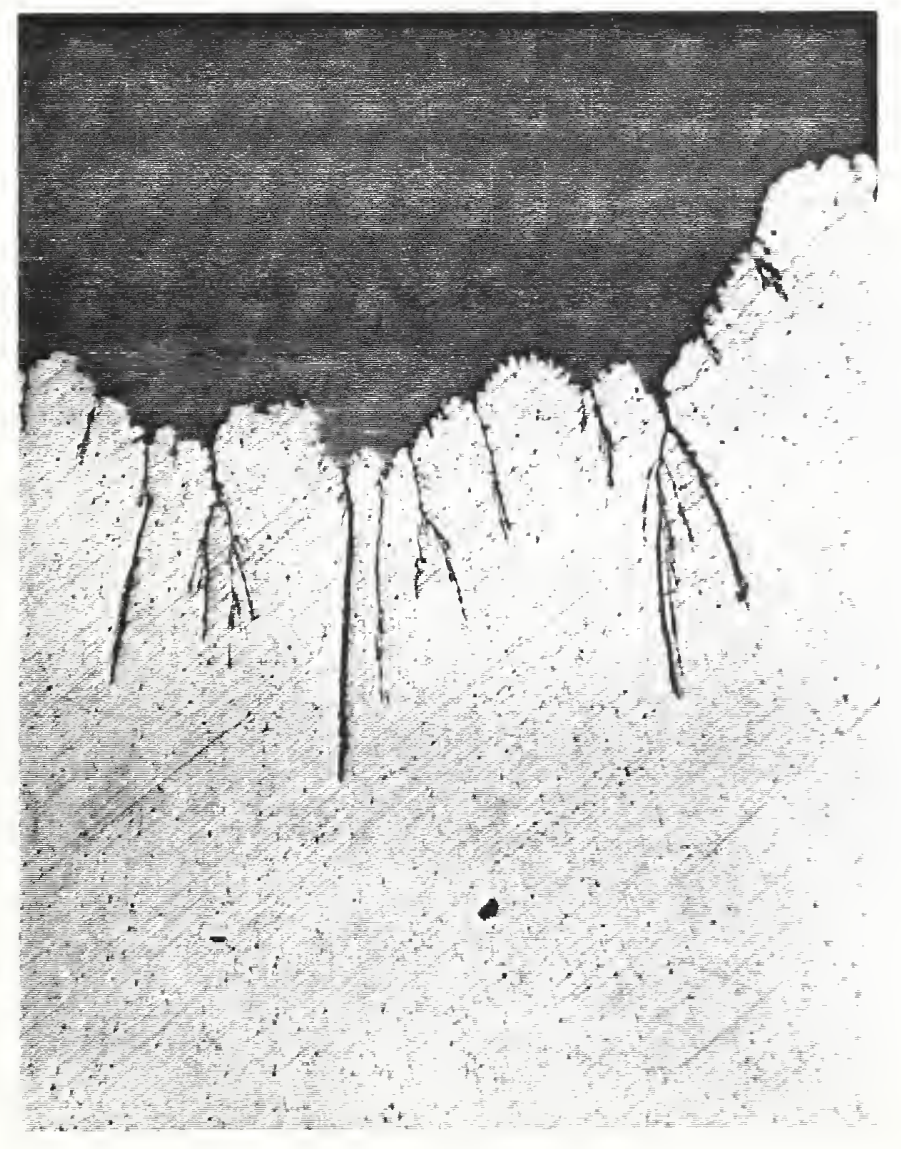

Primary Crack in Cylinder Neck

Cyl. No. T-262190 Mag. 40x

Fig. 17 


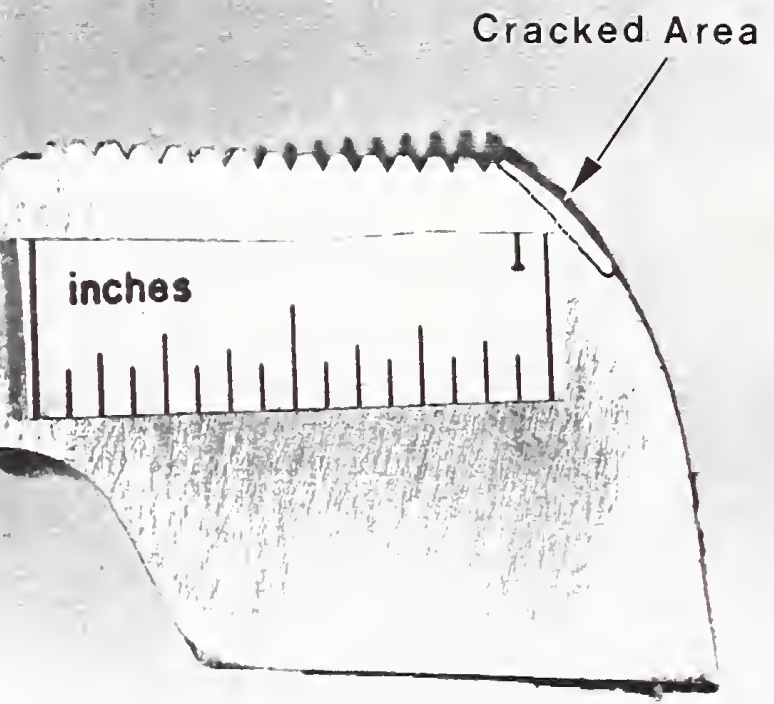

Extent of Primary crack

Cyl. No. T-262190

Fig. 18 


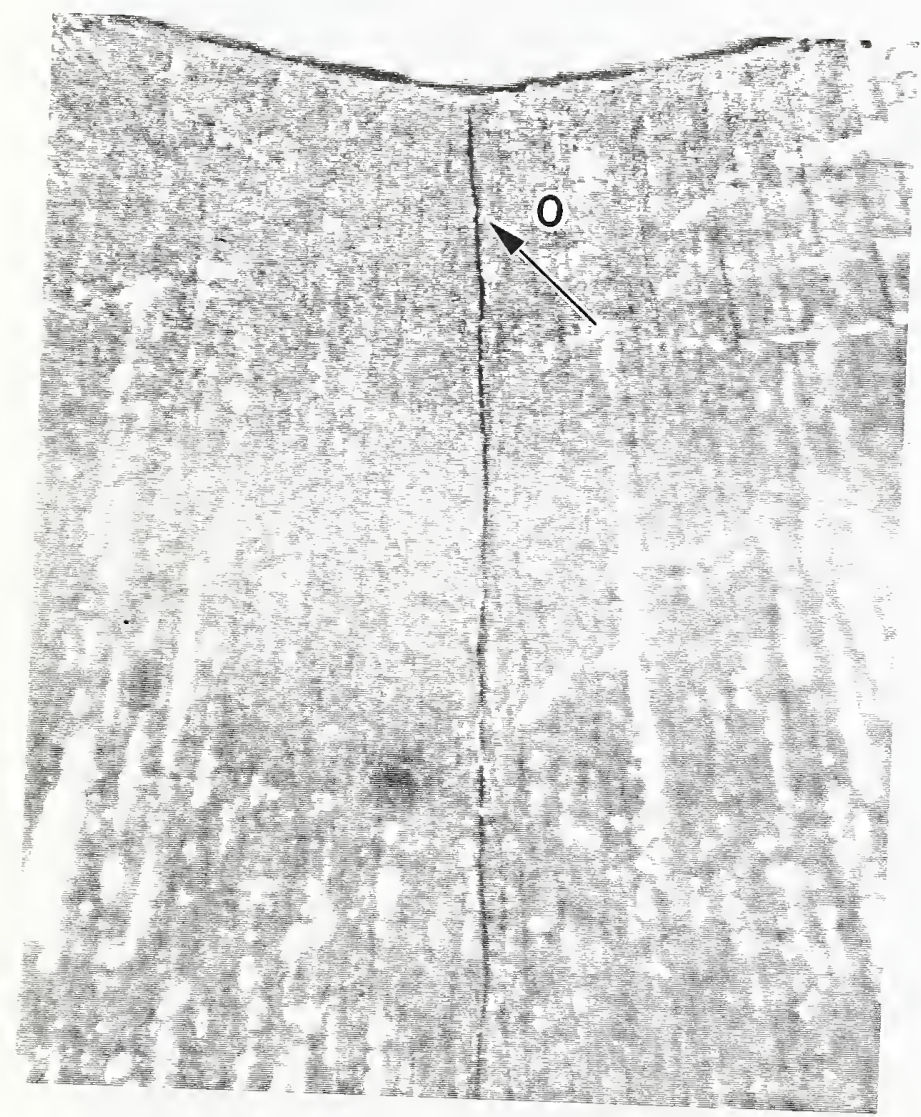

Crack-Like Indication

Cyl. No. T-256255 Mag. 12x

Fig. 19 


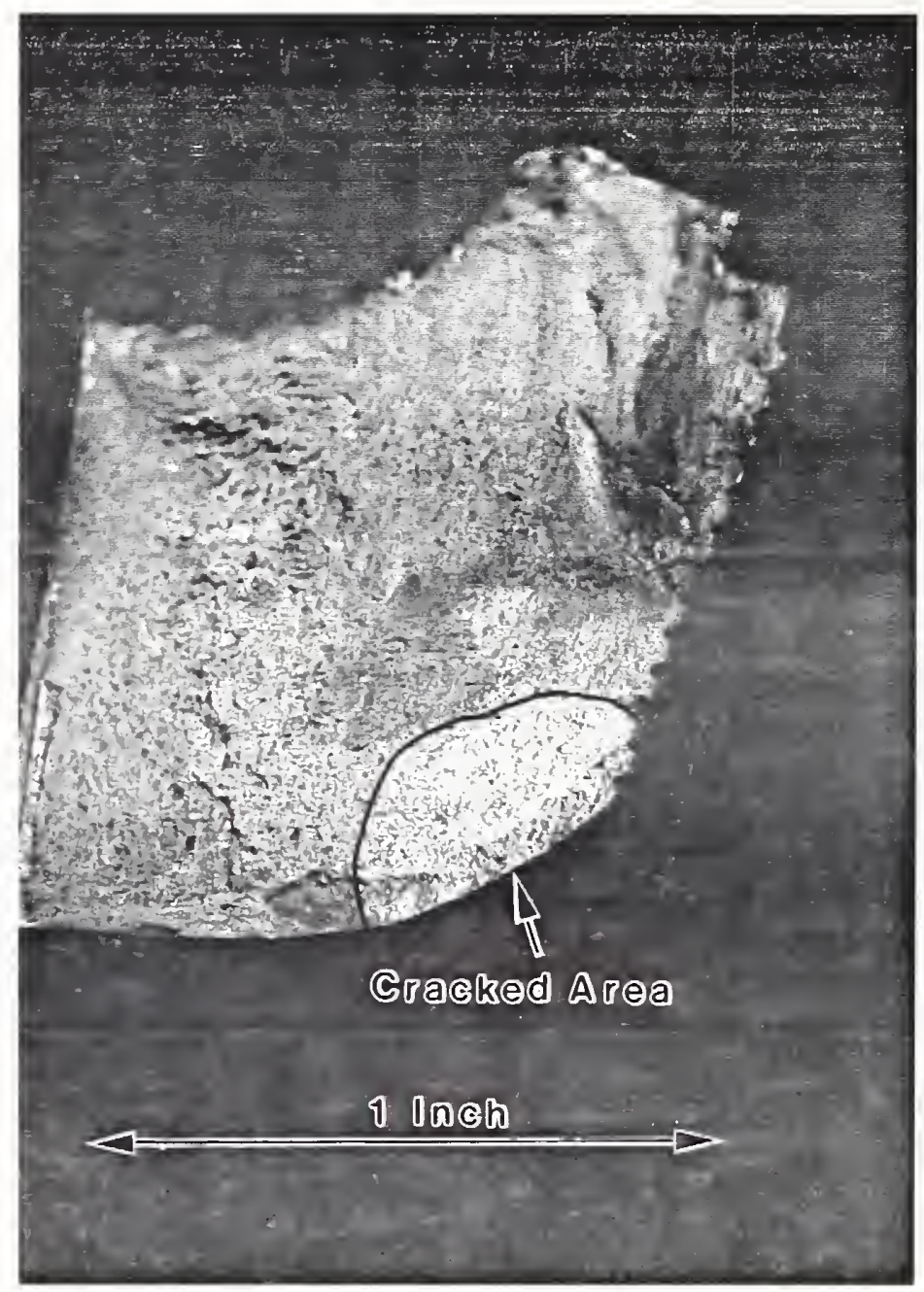

Extent of Primary Crack

Three-Point Bend Specimen

Cyl. No. T-256255

Fig. 20 


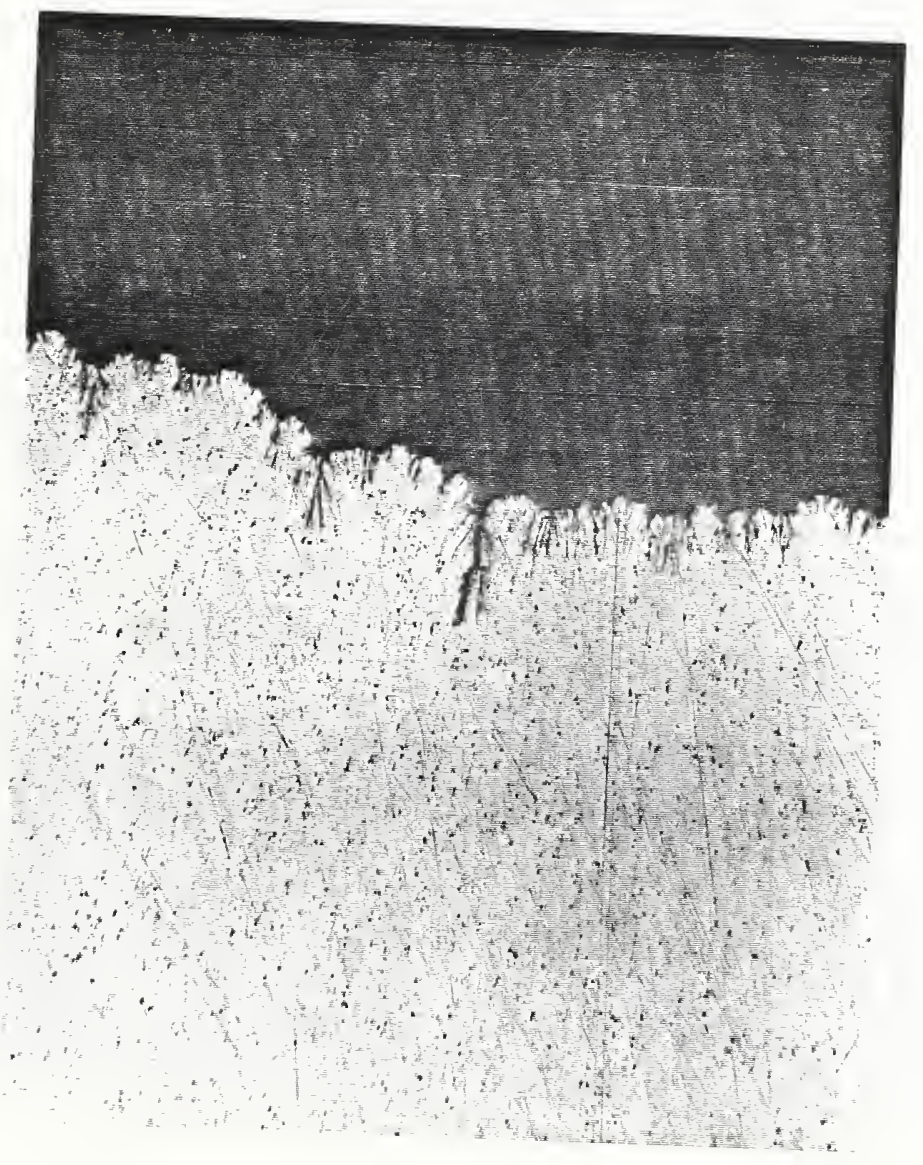

Crack at Position ' 3 '

Cyl. No. T-256255 Mag. 40x

Fig. 21 


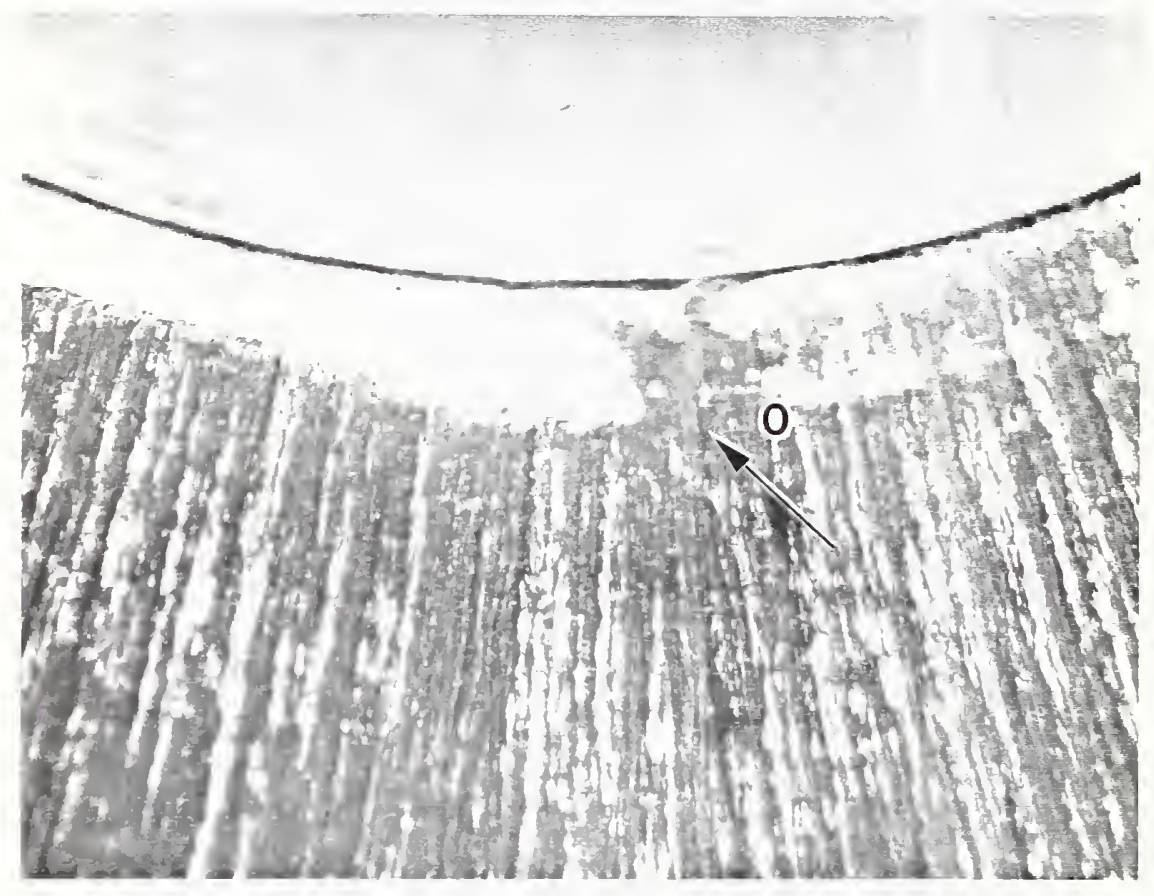

Crack-Like Indication

Cyl. No. WK-31111 Mag. 12x

Fig. 22 


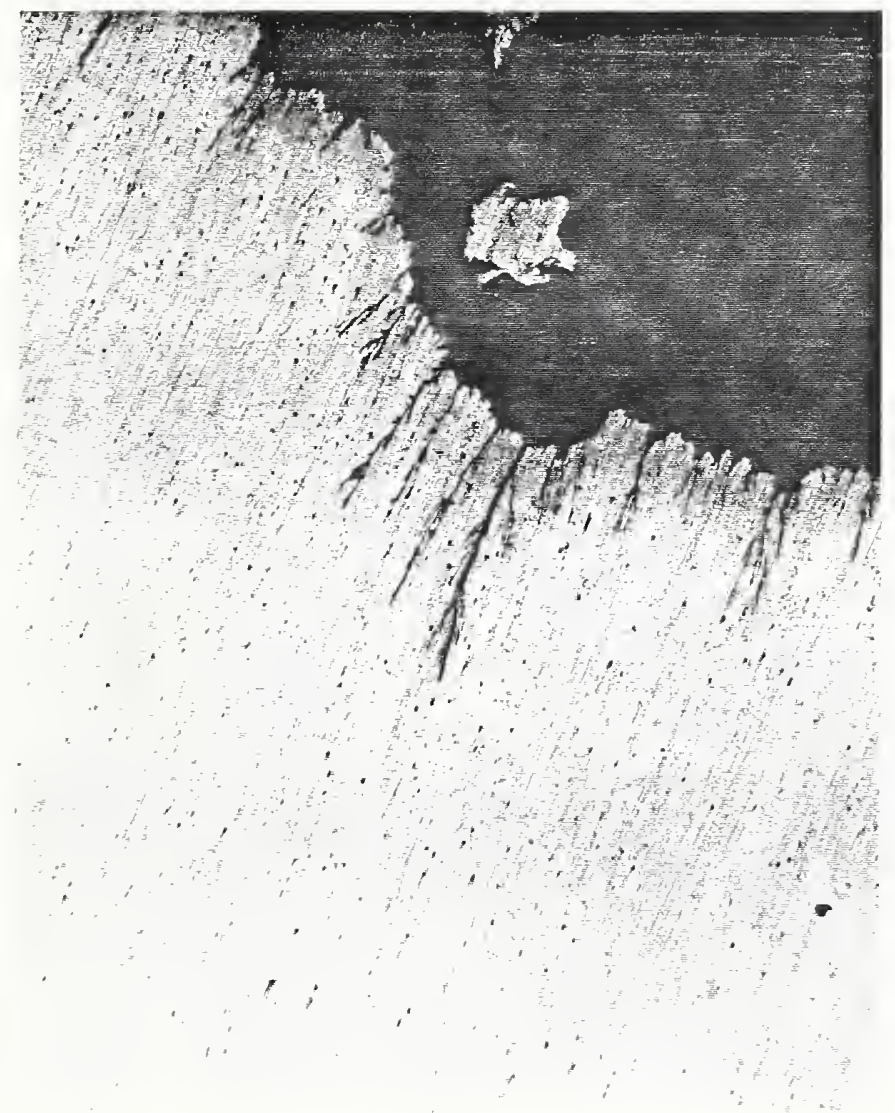

Primary Crack in Cylinder Neck

Cyl. No. WK-31111 Mag. 40x

Fig. 23 


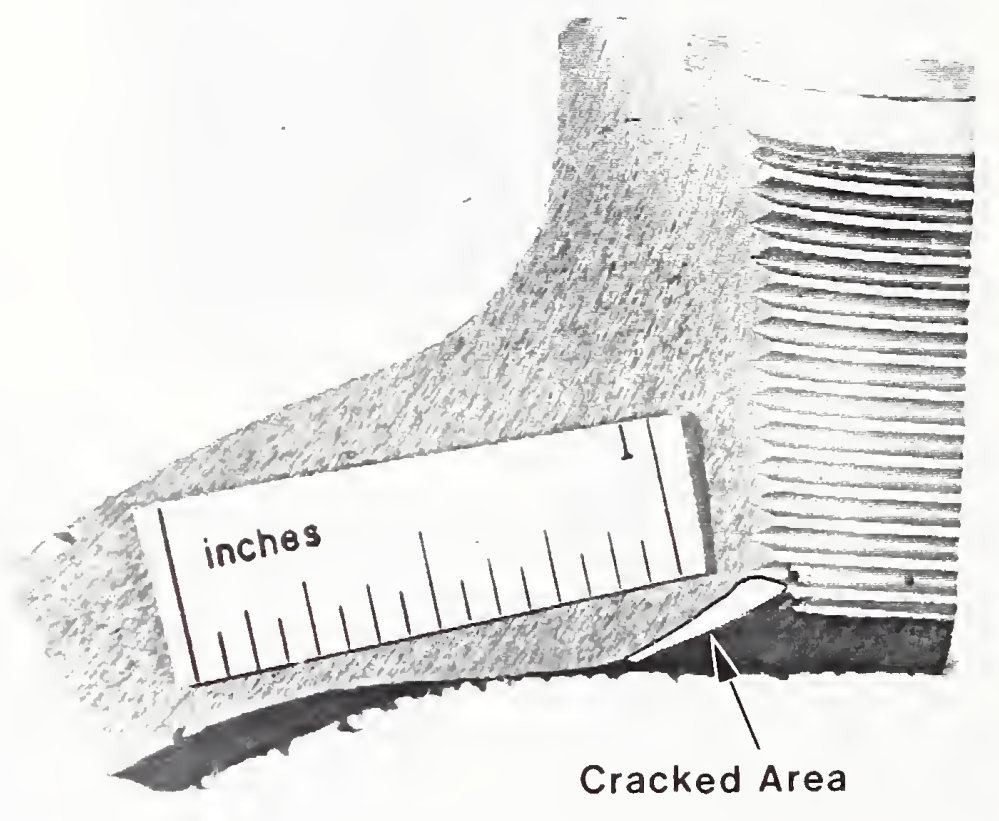

Extent of Primary Crack

Cy1. No. WK-31111

Fig. 24 


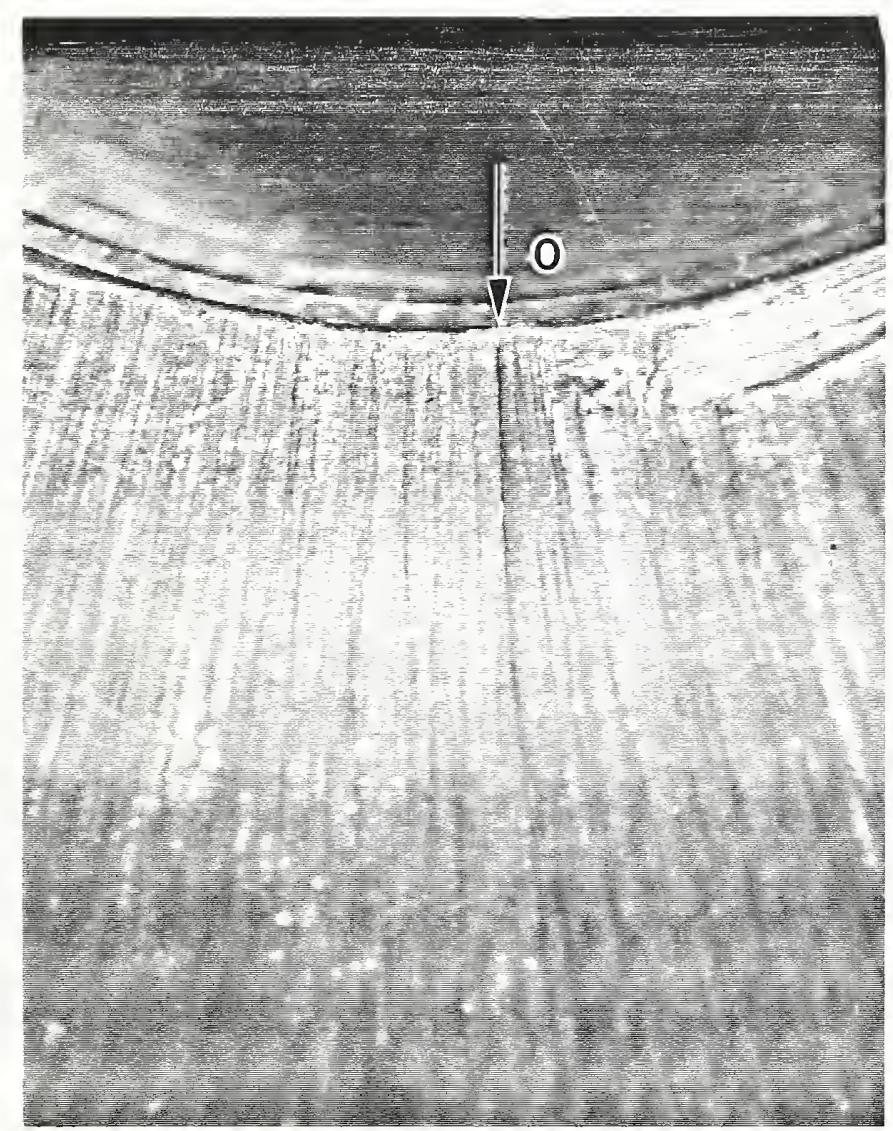

Crack-Iike Indication

Cyl. No. WK-32699 Mag. 10x

Fig. 25 


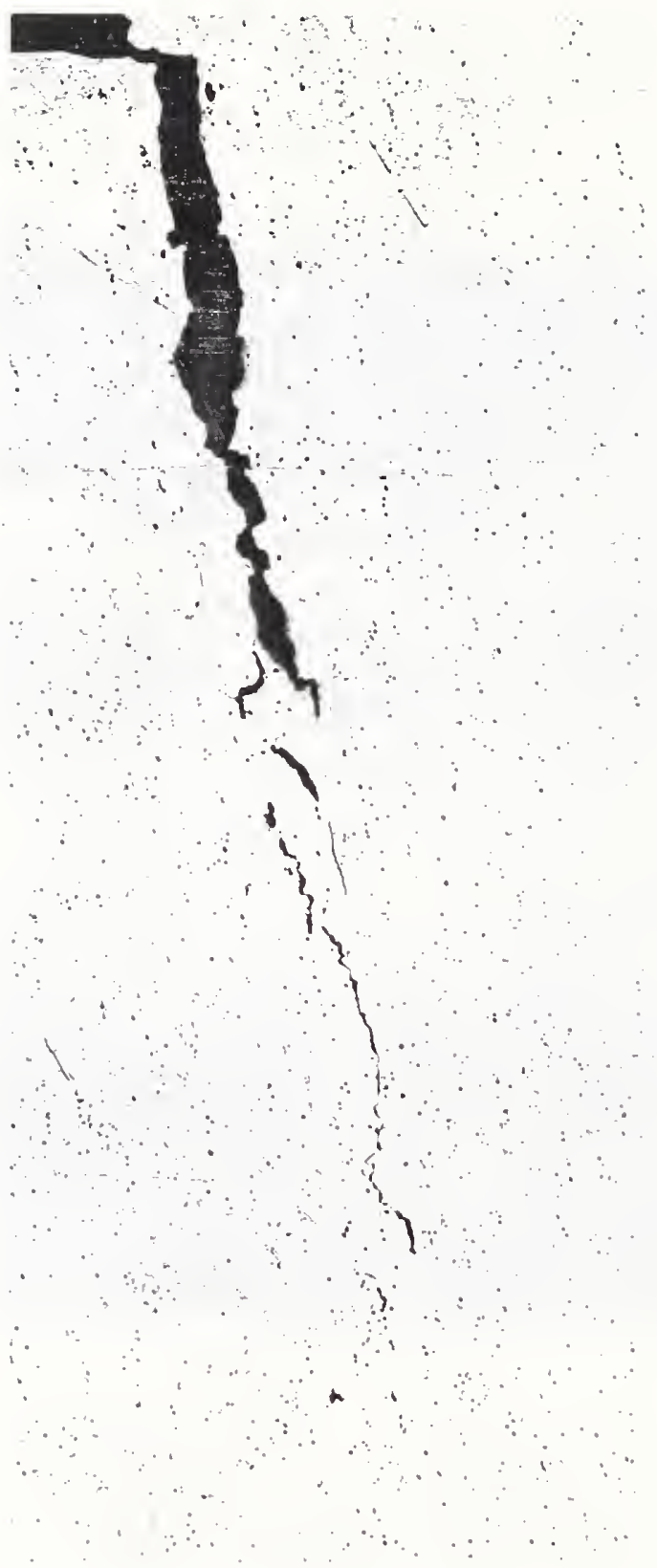

Primary Crack in Cylinder Neck CYl. No. WK -32699 Mag. 40x

Fig. 26 


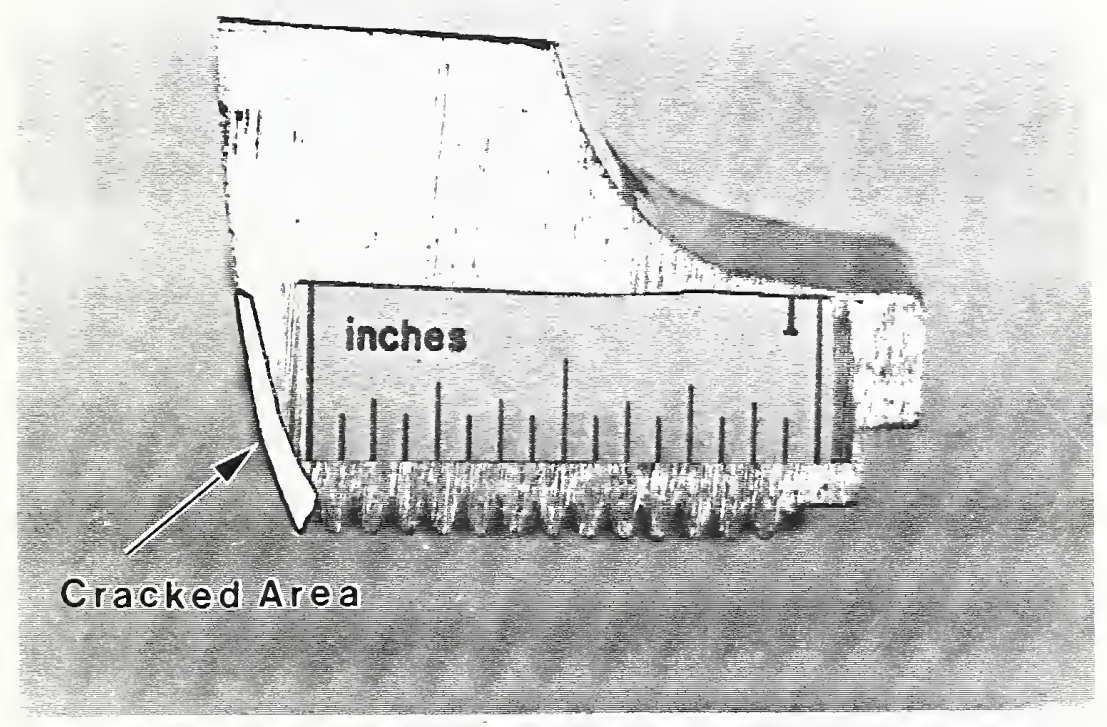

Extent of Primary Crack

CYl. No. WK-32699

Fig. 27 


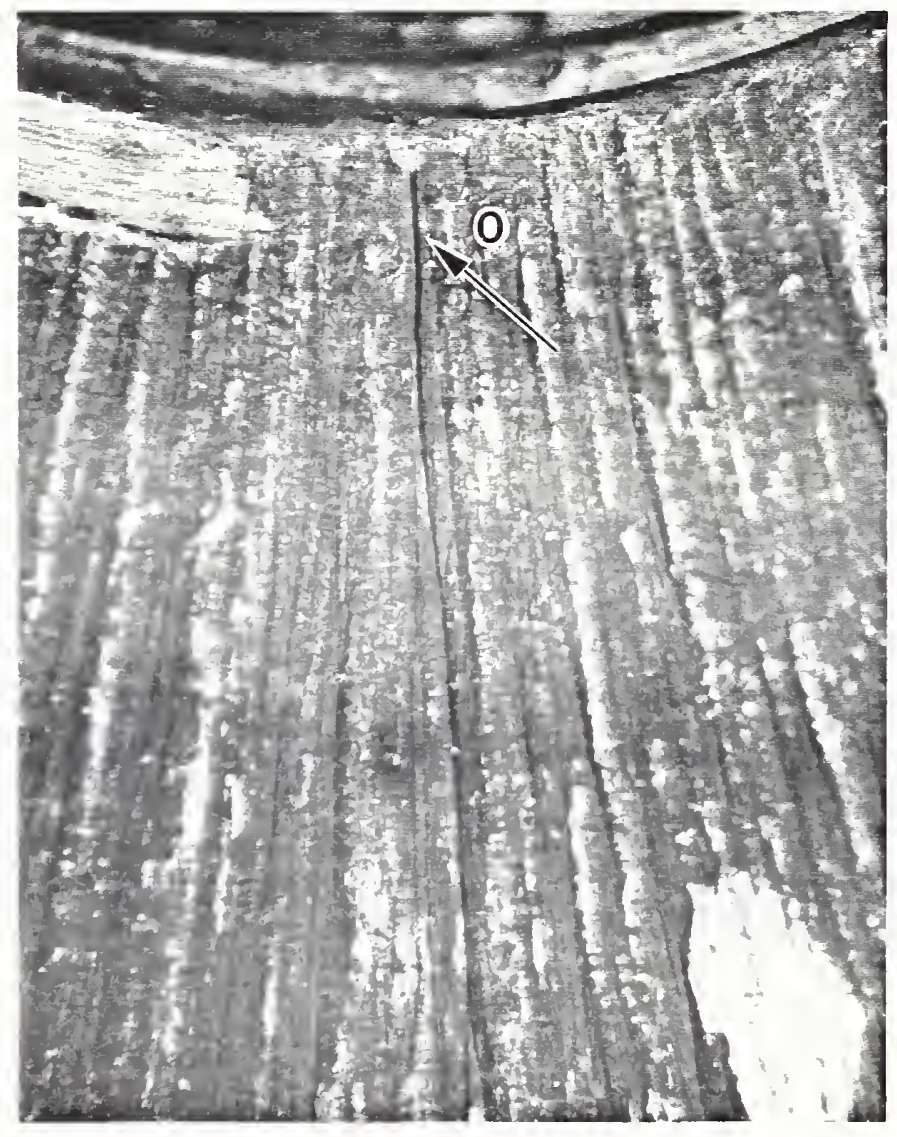

Crack-Like Indication

Cyl. No. WK-31631 Mag. 12x

Fig. 28 


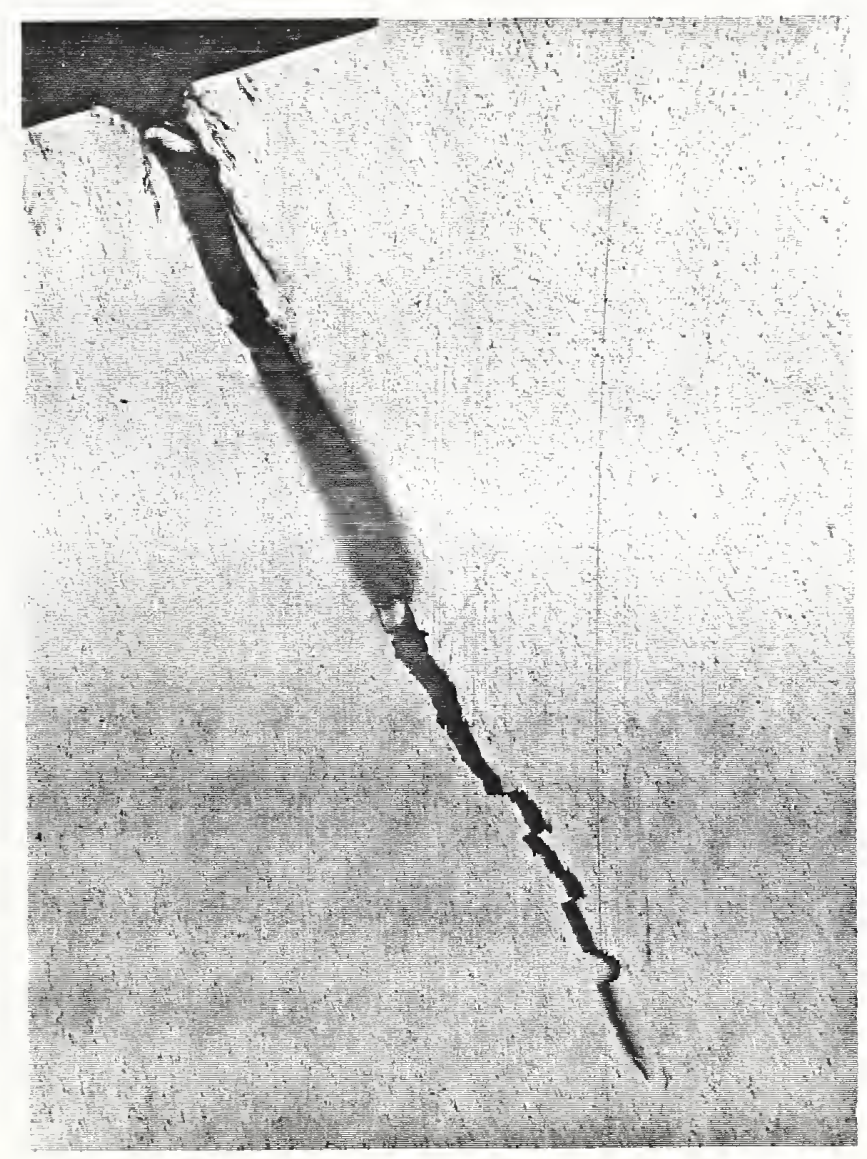

Primary Crack in Cylinder Neck

Cyl. No. WK-31631 Mag. 18x

Fig. 29 


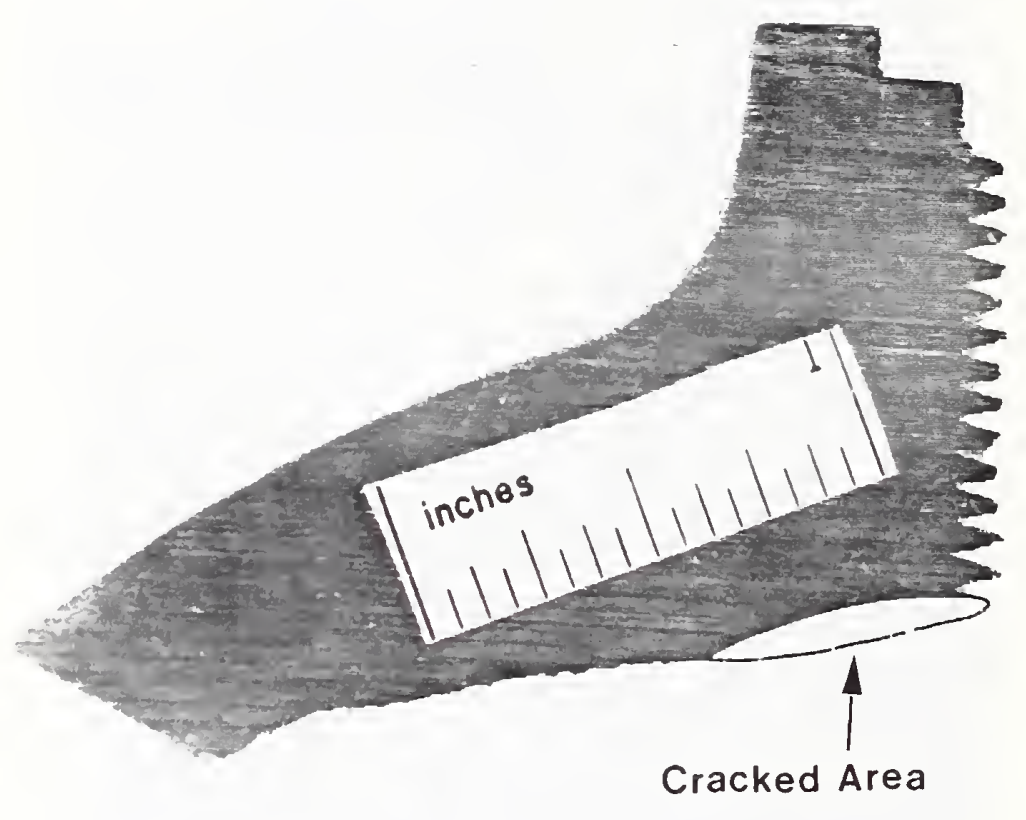

Extent of Primary Crack

Cyl. No. WK-31631

Fig. 30 
IBS-114A (REV. 2-80)

U.S. OEPT. OF COMM.

BIBLIOGRAPHIC DATA

SHEET (See instructions)

1. PUBLICATION OR REPORT NO.

$86-3492$

2. Performing Organ. Report No of 3. Publication Date

March 1987

4. TITLE AND SUBTITLE

Evaluation of Cracking in Aluminum cylinders

5. $\operatorname{AUTHOR}(\mathrm{S})$

John H. Smith

6. PERFORMING ORGANIZATION (If joint or other than NBS, see instructions)

NATIONAL BUREAU OF STANDARDS

U.S. DEPARTMENT OF COMMERCE

GAITHERSBURG, MD 20899

7. Contracd Grant No.

DTRS 5683

8. Type of Report \& Period Covered

Final

9. SPONSORING ORGANIZATION NAME AND COMPLETE ADDRESS (Street, City, State, ZIP)

Research and Special Programs Administration

U.S. Department of Transportation

4007 th Street, S.W.

Washington, D.C. 20590

10. SUPPLEMENTARY NOTES

Document describes a computer program; SF-185, FIPS Software Summary, is attached.

11. ABSTRACT (A 200-word or less factual summary of most significant information. If tocument includes a significant bibliography or literature survey, mention it here)

Cracking was first observed in the threaded area of high pressure (4500 psi)

fiberglass-wrapped composite-aluminum compressed gas cylinders and has

resulted in the leaking and rupture of a few of these cylinders in the last

three years (Ref. 1). More vecently, the neck and threaded area of some

fiberglass-wrapped composite-aluminum and some seamless aluminum (type 3A1)

cylinders have been visually inspected during the normal periodic retest.

As a result of this visual inspection at the time of retesting, several

aluminum cylinders were reported to show evidence of cracking in the neck and

threaded area. A group of these cylinders was obtained for more detailed

laboratory examination to determine the extent of the cracking and to

attempt to assess the significance of the cracking. This report describes

the results of the laboratory tests on this group of cylinders that were

reported to have cracks.

12. KEY WORDS (Six to twelve entries; alphobetical order: copitalize only proper names; and separate key words by semicolons)

a luminum; aluminum alloy no. 6351; pressure vessels; sustained load cracking

13. AVAILABILITY

X Unimited

For Official Distribution. Do Not Release to NTIS

Order From Superintendent of Documents, U.S. Government Printing Office, Washington, D.C. 20402.

14. NO. OF

PRINTED PAGES

51

X Order From National Technical Information Service (NTIS), Springfield, VA. 22161

$\$ 13.95$ 


